REVISTA DE DERECHO UNED, NÚM. 14, 2014

\title{
RELACIONES DE LA ADMINISTRACIÓN Y EL SECTOR PRIVADO EN LA ADAPTACIÓN JURÍDICA A LA GESTIÓN DE LOS SERVICIOS PÚBLICOS
}

\author{
RELATIONS OF THE ADMINISTRATION AND THE PRIVATE \\ SECTOR IN THE LEGAL ADAPTATION TO THE MANAGEMENT \\ OF PUBLIC SERVICES
}

\section{JULIÁN TORRADO SANCHO}

Licenciado en H. ${ }^{\text {a }}$ Moderna y Contemporánea. UAM. DEA. Doctorando en Derecho. UNED

Resumen: Se considera a la modernización administrativa un proceso histórico concreto en el que se producen transformaciones en la gestión pública de los Estados liberal-democráticos de los que España forma parte. Su principal característica procede de la modificación en las formas de prestación de los servicios públicos, que afectan a dos dimensiones respecto a sus antecedentes inmediatos, por una parte la privatización de sus relaciones con el entorno social y por otra la tecnificación de sus métodos de organización y gestión. Si bien la Administración pública es el sujeto de dichos cambios basados en políticas públicas destinadas a ella, su marco jurídico constituye el objeto más relevante para el funcionamiento del Estado de Derecho, sustrato definitorio de la eficacia y razón de ser de su organización y actividad.

Abstract: The administrative modernization is considered a concrete historical process in which changes occur in the public management of democratic liberal states of which Spain is a part. Its main feature is from the change in the ways of delivering public services, involving two dimensions relative to its immediate antecedents, on the one hand, privatization of its relationship with the social environ- 
ment and on the other the modernization of its methods of organization and management. While public administration is the subject of such changes based on public policies aimed at her, its legal framework constitutes the most important object for the operation of the rule of law, definitor of the efficacy and rationale of its organization and activity.

Palabras Clave: Administración pública, derecho administrativo, derecho constitucional, nueva gestión pública, derecho privado, reforma administrativa, gobernanza, intervención pública, estado social, privatización.

Keywords: Public administration, administrative law, constitutional law, new public management, private law, administrative reform, governance, public intervention, welfare state, privatization.

Recepción original: 26/03/2014

Aceptación original: 29/04/2014

Sumario: I. Nuevos principios rectores en las relaciones de la administración y el ámbito privado ante la transformación de la gestión pública I.1. Ejes de la interrelación entre los principios públicos y la legitimidad privada I.2. Efectos antijurídicos de la legislación en la modernización y necesidad de nuevos planteamientos II. Adaptación de las relaciones jurídicas en la organización y gestión de los servicios públicos II.1. Condiciones jurídicas de las relaciones entre Administración y ciudadanos en la organización II.2. Efectos de la responsabilidad administrativa en la descentralización de los servicios públicos III. Dinámica jurídica del derecho administrativo en la implantación de las técnicas de gestión pública III.1. Los nuevos desarrollos normativos III.2. Las normas técnicas en el marco jurídico público.

I. NUEVOS PRINCIPIOS RECTORES EN LAS RELACIONES DE LA ADMINISTRACIÓN Y EL ÁMBITO PRIVADO ANTE LA TRANSFORMACIÓN DE LA GESTIÓN PÚBLICA

\section{I.1. Ejes de la interrelación entre los principios públicos y la legitimidad privada}

La nueva propuesta de interrelación pública y privada, tras la dilución del Estado del bienestar e interventor en la década de los setenta del siglo XX, encuentra su legitimidad en el reforzamiento de ciertos ejes de interrelación que contrae la iuspublificación de su ac- 
tividad. En este sentido, el Estado ampara su legitimidad en principios constitucionales cuya traslación desde el Derecho público al ámbito privado merece ser tomada en consideración, pues presenta importantes elementos nuevos inequívocamente incorporados desde dichos principios ${ }^{1}$.

Uno de los rasgos característicos en la recepción de las profundas y continuas reformas que sostienen el proceso de modernización administrativa viene significado por los cambios legislativos que acompañan el nuevo marco jurídico de la gestión pública y, sin embargo, la escasa afectación de los sistemas constitucionales, salvo por razones de actualización de la organización territorial, o por incorporación de ciertos Estados al régimen liberal-democrático. Por lo tanto, no se trata aquí de delimitar tan amplios principios del Derecho público, motivo de los más extensos tratados y fuentes de fundamentación de la doctrina jurídico pública, sino situar aquellos conectados con la cooptación de que son objeto en el nuevo contexto de relaciones entre el ámbito público y privado en el proceso de modernización de la Administración pública.

\section{I.1.A. El principio de libertad económica}

El principio de libertad económica queda garantizado en la obligación de tutela por los poderes públicos de los Derechos y Libertades (Tít. I. Cap. II. Constitución Española, en adelante CE) con el reconocimiento del derecho a la propiedad privada (art. $33 \mathrm{CE}$ ) y a la libertad de empresa (art. $38 \mathrm{CE}$ ), que se conjugan con la imparcialidad y sujeción a la legalidad de la Administración Pública en el servicio objetivo a los intereses generales (art. 103.1 CE). Si bien el artículo 33 establece en el apartado segundo la reserva legislativa de toda limitación del derecho a la propiedad por su función social y en el apartado tercero por «causa justificada de utilidad pública o interés social», así como el artículo 38 establece la garantía y protección de este derecho sujeto a la «defensa de la productividad, de acuerdo con las exigencias de la economía general y, en su caso, de la planificación», queda claro por lo tanto su reconocimiento entre los derechos fundamenta-

${ }^{1}$ Artículos 33.1 y $38 \mathrm{CE}$ respecto al principio de libertad económica, art. 103.1 CE respecto al principio y deber de eficacia y artículo 33, que en su apartado segundo pone en conexión la propiedad privada con la función social y en el apartado tercero da preeminencia a la utilidad pública o interés social sobre el derecho a la propiedad privada en el que se puede encontrar la conexión con el nuevo eje de responsabilidad social adoptado por las actividades privadas empresariales, al que desde luego se deben vincular otras motivaciones ligadas a su propia naturaleza privada. 
les y las libertades públicas (Tít. I. Cap. II. Secc. 1. ${ }^{a} \mathrm{CE}$ ), que informan con la máxima jerarquía normativa a todo el ordenamiento jurídico, como criterio regulador de la actuación pública. Respecto a la conjugación con el artículo 103, que rige el principio general de funcionamiento de la Administración, más allá de su posible invocación al orden jurisdiccional en su «sometimiento pleno a la Ley y al derecho», permite a la actividad administrativa limitar la actividad privada en aplicación del principio de eficacia en cualquiera de sus disposiciones o actos, ejecutando así, entre otras, cualquier decisión concreta y fundamentada sobre la utilidad pública, el interés social, las exigencias de la economía general o la planificación ${ }^{2}$. Ante los posibles márgenes de discrecionalidad, obligados por los supuestos de imperiosa necesidad que arrastran esos límites, los principios de objetividad y sometimiento a la Ley y el Derecho suponen la base de una factible conjugación de múltiples intereses privados en presencia.

El reconocimiento del principio de libertad económica del Estado liberal viene causado por la concentración del poder económico en el poder político durante el Antiguo Régimen, cuyas normas se dirigen a proteger las relaciones que asignan derechos y obligaciones desiguales en la sociedad bajo el sistema de privilegios. Sin embargo, una vez corregidos éstos por el sistema liberal, el ejercicio de la propiedad privada en un régimen jurídico absentista tiende a alterar materialmente el principio de igualdad ante la ley, basada formalmente en la protección pública del ejercicio de la libre actividad económica, el patrimonio privado y el gasto orientado al fomento de la actividad mercantil. Así, las desigualdades económicas fácticas restringen la libre adopción de los acuerdos privados, por prescindir el citado absentismo político de dar protección jurídica material a la igualdad de las partes. La mayor parte del ordenamiento jurídico se dirige, por consiguiente, a la tutela y el fomento de la propiedad, que se acumula

${ }^{2}$ Respecto al artículo 33 corresponden al ámbito legislativo de la Administración las leyes de expropiación que constituyen uno de los bloques de contenidos típicos en los que la doctrina clasifica la actividad administrativa, al artículo 38 podrían asociarse en el mismo orden, entre otras, a la actividad promocional o de fomento y la legislación de planificación económica, implícita cuando menos en las leyes presupuestarias del Estado y su Administración y las aplicaciones fiscales ejecutadas por las diferentes administraciones tributarias. A estas últimas pueden agregarse todas las normas de privatización que corresponden a la gestión de los bienes públicos que evidencian la exigencia del requisito de objetividad tanto en los procedimientos de enajenación de dichos bienes como en la misma contratación pública. Vid. DorRego DE CARLOS, Alberto y MarTínez VÁzouez, Francisco. «La colaboración público-privada» en La colaboración público-privada en la Ley de Contratos del Sector Público. Aspectos administrativos y financieros, (Dtores. Alberto Dorrego de Carlos y Francisco Martínez Vázquez) y (Coord. Jorge Villarino Marzo). La Ley, Madrid, 2009. pág. 47. 
en sectores minoritarios de la sociedad. Como consecuencia práctica la Ley no sirve a todos por igual y permite, por el estado de necesidad, la imposición de condiciones desproporcionadas en las formalmente libres relaciones contractuales.

Las correcciones graduales de este marco jurídico, motivadas indudablemente bajo la presión de los movimientos sociales que acompañan las transformaciones políticas, se sustancian en el desarrollo jurídico positivo de los derechos sociales y la intervención del Estado en un largo proceso que abarca, en su sentido más amplio, casi un siglo $^{3}$. Este fenómeno de reconocimiento material de los derechos sociales queda a su vez sometido, ante la crisis estructural en la década de los setenta del siglo XX, a la posterior revisión de las políticas públicas que vuelven a retomar, bajo nuevas premisas, el principio de libertad económica, y en relación con esas políticas, la gestión pública que se somete a procesos de privatización ${ }^{4}$.

\footnotetext{
${ }^{3}$ Es interesante en este punto traer a colación la delimitación entre los derechos y prestaciones sociales derivadas de éstos y los servicios sociales cuya precedencia radica en el ámbito de la acción social. Juan-Cruz Alli Turrillas, que estudia su situación jurídica y antecedentes históricos, los sitúa con acierto en una categoría de prestaciones cualitativamente distintas cuyo substrato cultural reside en el principio religioso de la caridad cristiana. Destaca su carácter voluntario que se incorpora tempranamente el Estado liberal a través de la Beneficencia. Si bien el desarrollo de ésta confluye en parte con las conquistas de los derechos sociales y sus prestaciones consecuentes, siendo un antecedente indudable entre otros de la Seguridad Social obligatoria, siempre cabe distinguir, - desde su origen y aún en la actualidad- a este bloque de prestaciones de las denominadas de bienestar social o servicios sociales. Con todo, resulta difícil no establecer relación entre ambos desarrollos como un conjunto o sistema y los movimientos sociales de los sectores asalariados a fines del siglo XIX. Vid. AlLi TurRILlas, Juan Cruz. "Capítulo XI. La intervención de la Administración en el ámbito de la acción social» en Parte especial del Derecho administrativo. La intervención de la Administración en la sociedad, (coord. Enrique Linde Paniagua). Madrid, Colex, 2007. págs. 607-636.

${ }^{4}$ En cuanto a un modelo típico de prestación social encontramos la Sanidad, aquí Jesús Fuentetaja Pastor ilustra sobre el carácter regulatorio de su desarrollo normativo, legislativo y reglamentario, a partir del mandato constitucional del artículo 43 $\mathrm{CE}$ que lo informa «...la importancia de la acción sanitaria superó incluso su concepción y articulación como servicio público para pasar a constitucionalizarse como derecho a la protección de la salud, perspectiva desde la que será necesario e imprescindible afrontar la regulación y el estudio de la sanidad. Especialmente teniendo en cuenta que ni el servicio público ni su calificación como derecho constitucionalizado permiten sustraer a la sanidad del mercado». En este sentido se trata de un servicio público que sirve directamente a la protección de un Derecho social -principio rector de la política social- consagrado en toda su extensión en el citado artículo $43 \mathrm{CE}$, especialmente en la garantía que se introduce en el párrafo segundo. A los efectos de la discusión entre intervención y regulación este servicio presenta, como destaca Fuentetaja, su carácter privado originario y por ende su existencia previa en el mercado. La conjugación de ambas realidades se complejiza cuando en la parte del servicio público garantizador se procede a la privatización parcial mediante las formas
} 
Los fenómenos de desarrollo privatista del sector público y su parangón en la liberalización económica nacen por consiguiente de ese importante principio. Así, tras un periodo de intervención pública marcada por el Estado de bienestar, son las medidas de desregulación, fuertemente impulsadas por las políticas y el desarrollo de las normas europeas, las que han devuelto el criterio rector de la libertad económica a la ejecución de las políticas públicas. El esquema neoliberal parte, por otro lado, de una nueva realidad más compleja que el liberalismo inicial, debido, entre otros, a los procesos de privatización del patrimonio público, que exigen una profunda regulación ${ }^{5}$.

\section{I.1.B. El principio de eficacia y eficiencia}

En el proceso de modernización administrativa se puede destacar como segundo eje de interrelación el principio de eficacia, recogido como concepto de gestión desde el principio jurídico público ${ }^{6}$ Tal vez, esa regulación que exigen los procesos de privatización material, a diferencia de la privatización formal cuyos procesos son en realidad meramente liberalizadores, no se limita a la acción externa, sino que interviene internamente en la gestión pública, transformando el concepto de eficacia al prescindir en la gestión pública de instrumentos jurídicos propios y dejar paso en ella a nuevos mecanismos técnicos importados del sector privado. Mecanismos propiciados en gran medida por las transformaciones en la innovación científica y tecnológica motivados por las carencias y limitaciones de aquellos instrumentos jurídicos utilizados en exclusividad. En este sentido, el concepto de eficacia jurídica abre paso a la eficacia en la gestión, al public management y las disciplinas y teorías de la organización y la Adminis-

jurídicas públicas, destacadas por el autor, de concesión y concierto. (FUENTETAJA Pastor, Jesús y Medina González, Sara. «Capítulo XIX. La intervención de la Administración en la Sanidad» en Parte especial del Derecho administrativo. La intervención de la Administración en la sociedad, (coord. Enrique Linde Paniagua). Madrid, Colex, 2007. 1189-1252).

5 «Señala la doctrina que privatización y regulación vienen siempre unidos; cuando la Administración deja de operar de forma directa en el mercado, somete el mismo a una regulación encaminada a subsanar sus fallos, reservándose facultades de policía y correctoras sobre los agentes intervinientes en él». (MONTERo ElENA, Concepción Mónica. «Empresa pública y privatización» en La intervención administrativa en la economía (Dir. Germán Fernández Farreres). Madrid, Consejo General del Poder Judicial, 1996. pág. 78).

${ }^{6}$ «[...] una acción es eficaz si consigue el objetivo deseado. Esta idea la hace suya la Administración en la actualidad, ante el objetivo necesario de racionalizar el gasto público». (VIlla-Real Molina, Ricardo y Del Arco TorRes, Miguel Ángel. Diccionario de Términos Jurídicos. Granada, Editorial Comares, 2006. pág. 179). 
tración desarrolladas en el estudio del sector público iniciado en el apogeo del Estado del bienestar y la crítica a la burocracia. Quizás, ya no se trata de un mero Estado absentista, pues los intentos de imposición radical de la liberalización económica por la Nueva Gestión Pública (NGP) entran en crisis ante sus propias contradicciones en la década de los noventa del siglo XX, sino de un Estado que interviene en la sociedad mediatizado por las corporaciones y los grupos de interés privado, pero que, en definitiva, debe atender conjuntamente con eficacia las necesidades y demandas de una sociedad compleja en discontinua pero persistente evolución ante los avances tecnológicos y económicos que condicionan al conjunto de la actividad social.

Respecto a la correspondencia de esa eficacia en la acción externa de las políticas públicas del Estado y la Administración, se presentan en coherencia con los postulados que llevan a las reformas en el sector público. Dicha conexión se deduce del objeto de los procesos de privatización y liberalización en la producción y servicios de pertenencia al ámbito competencial o patrimonial de la Administración. Sin que aquí importe la regulación jurídica pública o privada, pues el vínculo con la primera quedaba establecido en su origen y tutela por los poderes públicos y la autoridad administrativa, basada como mínimo en la doctrina de los actos separables o la aplicación de técnicas del Derecho administrativo privado, cuando no sujetos completamente al Derecho administrativo.

En esencia, la liberalización ha buscado introducir mayor eficiencia en la prestación de estos servicios a través del aumento de la competencia entre proveedores, en un proceso que ha ido acompañado en muchos países de la privatización de los antiguos monopolios públicos y que, implícitamente, prometía un cambio en la estructura de oferta, un incremento de la competencia entre proveedores, el fomento de la eficiencia de los operadores, una reducción generalizada de los precios y el desarrollo de la calidad de los servicios de las empresas?.

En realidad, el concepto de eficiencia sirve en su correlación dialéctica al mismo principio de eficacia, más allá de su distinción, tanto como la equivalencia que en el enunciado de Antón Costas encuentran, en el nivel sintético propuesto, liberalización y privatización. Lo sustantivo del concepto es la búsqueda por el Estado, mediante la privatización o liberalización de los monopolios públicos, de una eficiencia, (eficacia en sentido amplio), que permita aumentar la calidad

${ }^{7}$ Costas, Antón. «Regulación y calidad de los servicios públicos liberalizados» en GAPP, 32, Enero-Abril, 2005. pág. 9. 
en la prestación de los servicios, de los que se beneficia implícitamente la sociedad a la que el Estado sirve ${ }^{8}$.

\section{I.1.C. El principio de responsabilidad social}

Por último, en el tercer eje de interrelación entre el ámbito público y privado que aquí se propone, quedan y se abren hueco las demandas que surgen de las necesidades sociales, comunitarias y medio ambientales, que no renuncian a cumplir estándares de calidad de vida en gran medida asentados en el Estado del bienestar. En su sustitución, de algún modo, la pérdida de la capacidad de materialización del principio social por la acción pública debe ser reemplazada como forma de legitimación que el sector privado está obligado a cubrir en su ocupación del ámbito público. Surge aquí, entre otros, pero de forma paradigmática, el principio de responsabilidad social, que supone sin duda una aportación surgida del ámbito privado desde finales de los años setenta y adopta, a partir de finales de la década de los noventa, un marcado carácter plural en su definición y adopción por entidades nacionales e internacionales públicas, privadas de interés público y organizaciones empresariales. Importa en primer término su aplicación a las corporaciones privadas que Woods define en 1991 como, « $a$ business organization's configuration of principles of social responsibility, processes of social responsiveness, and policies, programs, and observable outcomes as they relate to the firm's societal relationships»9.

Su origen puede situarse, como gran parte de las figuras del ámbito empresarial, a mediados de siglo XIX con el movimiento cooperativo y las iniciativas surgidas del socialismo utópico, que cobran un impulso definitivo a finales de ese siglo, precedencia que no puede quedarse en una consideración retórica pues se debe retomar para aclarar ciertos conceptos vigentes en la actualidad ${ }^{10}$. Si bien toda la reglamentación que se origina desde estos tempranos momentos pasa al ámbito del Derecho civil y mercantil ${ }^{11}$, cuyo objeto escapa a esta

${ }^{8} \mathrm{Vid}$. Aguilera Izaguirre, Gustavo. «La calidad como parámetro de actuación de la Administración Pública» en Actualidad administrativa, n. 22, 2010. pág. 1

${ }^{9}$ Wood, Donna J. "Corporate social performance revisited» en Academy of Management Review, v. 16, n.4, 1991. págs. 691-718.

${ }^{10}$ Se considera que La Rochdale Equitable Pioneers Society, cuyos principios siguen vigentes en la actualidad, da origen al cooperativismo desde 1844.

${ }^{11}$ En España está vigente la Ley 27/1999 de Sociedades Cooperativas de España de 16 de julio. Debe considerarse que esta competencia se encuentra transferida a las Comunidades Autónomas que legislan sobre ella. Profundizando en sus antecedentes se encuentra Ley de Cooperación de 2 de enero de 1942 desarrollada por Decreto 11/1943 que aprueba su Reglamento. 
investigación, que trata de recoger desde el principio un área que va más allá de ese impreciso territorio de los límites de las disciplinas del Derecho cuando se regulan, como en este caso, aspectos de interés público $^{12}$.

Del mismo modo que se puede considerar ese antecedente de la economía social como una sustitución de la acción pública en el ámbito privado, que una vez surgida en éste es regulada jurídicamente con posterioridad, en la perspectiva que se pretende analizar, también la responsabilidad social supone una iniciativa empresarial que, ya en un escenario de marginalidad del Derecho administrativo, se adopta a través de entidades de Derecho internacional privado, e institucional público ${ }^{13}$. Todo ello no evita la aparición de un conjunto de disposiciones que en este ámbito recogen instrumentos como los informes institucionales, los dictámenes legislativos y otras fuentes no vinculantes a las que se antepone un marco regulador privado, pues si al principio posee un carácter voluntario, gradualmente se va incorporando a la práctica de las empresas y corporaciones. El siguiente aspecto de esta figura resulta de la autoimposición de obligaciones que corresponden a principios de responsabilidad pública, pero que en los mandatos constitucionales no superan las disposiciones orientativas no vinculadas a garantías jurisdiccionales. En este sentido, aparecen recomendaciones y ciertas legislaciones que van añadiéndose al marco jurídico, como sucedió con las prácticas de la economía social ${ }^{14}$. Así lo muestra el Código de Comercio francés que incorpora los pri-

${ }^{12}$ De hecho se pueden aplicar a las normas, como éstas del ámbito de la economía social, principios comunes al Derecho administrativo del mismo modo que sucede con el Derecho laboral, pues en las relaciones privadas interfieren órganos administrativos de regulación pública con su marco jurídico interno, en este caso el Ministerio o las Consejerías de Trabajo

${ }^{13}$ Son numerosas las instituciones de carácter internacional privado o público que comienzan a intervenir en la regulación de la Responsabilidad social: la OIT, especialmente respecto a la responsabilidad social interna en la protección de los derechos de los trabajadores sin descuidar otros ámbitos Vid. OIT. Declaración tripartita de principios sobre las empresas multinacionales. Ginebra, 2006. <http://www.ilo.org/ public/spanish/support/lib/resource/subject/csr.htm> (consultado el 4-6-2011); la OCDE, tratando de fijar recomendaciones que afectan ya el campo de la competitividad empresarial; o los organismos de certificación y normalización, decididamente volcados en este ámbito mediante la auditoría y expedición de marcas de acreditación de su cumplimiento, donde en materia de responsabilidad social se presenta la norma ISO 26000:2010. Tocado el tema monográficamente en la perspectiva de las entidades parapúblicas de normalización, Vid. UNE. La Revista de Aenor. Responsabilidad social. Madrid, n. 258, marzo, 2011.

${ }^{14}$ La Resolución del Parlamento Europeo, de 13 de marzo de 2007, sobre la responsabilidad social de las empresas: una nueva asociación 2006/2133 (INI) incorpora recomendaciones no legislativas a los Estados miembros. 
meros preceptos de esta índole, entre los que destaca en su artículo L225-102-1 el siguiente texto:

Les informations sociales et environnementales figurant ou devant figurer au regard des obligations légales et réglementaires font l'objet d'une vérification par un organisme tiers indépendant, selon des modalités fixées par décret en Conseil d'Etat. Cette vérification donne lieu à un avis qui est transmis à l'assemblée des actionnaires ou des associés en même temps que le rapport du conseil d'administration ou du directoire.

Aunque para algunos autores el conjunto de innovaciones legislativas en el Derecho laboral, mercantil y de regulación medioambiental pueden formar un corpus de responsabilidad social, se trata en realidad de un campo al que las organizaciones se adscriben de forma no preceptiva bajo el compromiso mínimo del cumplimiento de la legalidad, único verdaderamente exigible, junto a la aplicación de principios sociales y económicos que incluyen los métodos de funcionamiento interno ${ }^{15}$.

La responsabilidad social corporativa equipara a las organizaciones públicas y privadas como actores sociales y económicos, además constata la necesidad de colaboración ante el desbordamiento del control jurídico de los derechos sociales no garantizados por el sistema público que se sustancian en procedimientos y medios técnicos de gestión y control, como los regidos por los departamentos de observación y elaboración de memorias, y los organismos de certificación ${ }^{16}$. Ante ellos la responsabilidad social representa una oportunidad de las entidades privadas que se presenta, ante la falta de una regulación potestativa, como un factor competitivo, donde el cumplimiento de dichos compromisos es valorable por la sociedad y actúa a través del mercado a modo de jurisdicción privada que contribuye a la rentabilidad, estabilidad y sostenibilidad de la actividad empresarial a largo

${ }^{15}$ Para su incorporación al ámbito legislativo en España se ha preferido utilizar el término responsabilidad social empresarial tal y como figura en la LO 3/2007, de 3 de marzo para la igualdad efectiva de hombres y mujeres, en aplicación de los art. 9.2 y 14 CE como principios de actuación de los Poderes Públicos, derechos, deberes y medidas que afectan a los sectores públicos y privados. En esta norma del bloque de constitucionalidad se vinculan las disposiciones del Título VII a la figura de la responsabilidad social en los arts. 73 a 75, manteniendo el mencionado carácter voluntario, además de la autorización de hacer uso de la publicidad como claro incentivo para la rentabilidad ante su cumplimiento.

${ }^{16}$ Todo un intento de recopilar la dispersa normativa que puede constituir el bloque legal afectado por el concepto de responsabilidad social corporativa figura en la codificación de De LA TORRE GARCía, Carlos (ed). Responsabilidad social corporativa. Navarra, Códigos básicos-Aranzadi, 2008. Se trata de un intento de atribución legislativa y normativa a esta figura, por lo demás pendiente de concreción doctrinal y jurídica. 
plazo $^{17}$. Por lo tanto, es posible entender la consolidación de esta figura ante dos realidades: por una parte la ocupación de un marco vacío de garantías jurídicas de Derechos fundamentales de la cláusula social, que las nuevas organizaciones privadas en el desplazamiento del ámbito público pueden cubrir como un nuevo activo empresarial; por otra parte, la ausencia de garantías públicas permite desarrollar ese espacio como un factor competitivo más dentro de una sociedad que, tras la experiencia del Estado del bienestar, es receptiva ante la contribución voluntaria a la defensa de los valores comunitarios ${ }^{18}$.

Sin embargo queda claro que ante cualquier fallo en el conjunto, el sistema sólo admite una responsabilidad global y que en último término la responsabilidad subsidiaria en el terreno social, en el sentido amplio que incluye los factores económicos y ambientales, corresponde a los poderes públicos por los principios ya establecidos en el marco constitucional, donde el Título. I Capítulo III CE, asigna a estos poderes en cada uno de sus artículos las obligaciones deducidas del reconocimiento material de esos derechos sociales en la aplicación de los principios rectores de la política social y económica. Ante el ejercicio de esa responsabilidad parece desprenderse que corresponde a estos poderes disponer de garantías a través de sus políticas, y a la Administración, como su brazo material, su sustanciación en las actuaciones de control e intervención bajo los principios objetivos de un marco jurídico especial debidamente dotado de medios para su ejecución ${ }^{19}$.

17 «La memoria de sostenibilidad pretende dar cuenta de las actividades e impactos que la organización mantiene con su entorno socioeconómico, entendidas éstas con un enfoque de triple cuenta de resultados (económico, ambiental y social). De esta manera, los grupos de interés clave son conscientes, juzgan y premian -a través de sus decisiones de mercado- las políticas y estrategias adoptadas» (RuIZ, Isaac. «Transparencia y competitividad: un binomio necesario» en UNE. La Revista de Aenor, n. 258, marzo, 2011).

${ }^{18}$ En el campo del razonamiento económico de la responsabilidad social corporativa aparece este interesante análisis: Vid. ORLITZKY, Marc; SchMIDT, L. Frank y RYNES, Sara L. "Corporate Social and Financial Performance: A Meta-analysis» en Organization Studies. London, SAGE Publications, n. 24. págs. 403-441.

19 «A la postre, no son los derechos y libertades como pretensiones subjetivas un fin en sí mismos; su ejercicio ha de venir orientado, antes bien, a realizar la institución garantizada». Aquí se entiende que el concepto de institución garantizada expresa no exclusivamente los medios de prestación directa que garanticen el cumplimiento material de los derechos inspirados en los principios rectores sino al menos cualesquiera de los contenidos típicos de la actividad administrativa que puedan utilizarse para garantizar esos derechos. (LÓPEz PinA, Antonio. «Artículos 39 a 55 de la Constitución Española de 1978» en Comentarios a la Constitución Española de 1978, (dir. Oscar Alzaga Villamil). Madrid, Edersa, 1998. págs. 17-42). 


\section{I.2. Distorsiones jurídicas en la legislación de la modernización administrativa y necesidad de nuevos planteamientos}

\section{I.2.A. La proliferación normativa}

La inmersión del ámbito privado en el público puede que se acompañe de una tendencia general de ampliar la legislación que limite la capacidad de interpretación de los principios jurídicos tanto en el ámbito jurisdiccional como doctrinal ${ }^{20}$. El sustrato legislativo y reglamentario a menudo se va haciendo denso y lejos de proporcionar mayor seguridad jurídica va disminuyéndola en un entramado de normas que, especialmente en las disposiciones normativas de la Administración, aumentan la concurrencia de definiciones de los principios jurídicos y con ellas su ambigüedad o las meras contradicciones de las categorías que los forman. La polisemia conceptual no representa mayor problema en el debate científico, pues los puntos de vista confrontados suponen enfoques del objeto tratado que no hacen sino enriquecerlo y en su deliberación ampliar el conocimiento sobre el mismo. También el debate doctrinal en el Derecho o el resto de las ciencias sociales que abordan el mismo objeto: el Estado, la Administración, el ejercicio político y la gestión pública, están sujetos a la misma cualidad. El problema se encuentra en trasladar estas licencias del método científico al ámbito jurídico positivo, a las normas o a las resoluciones jurisdiccionales que, si bien por la propia naturaleza del objeto tratado, siempre estarán sujetas en su ejecución a la interpretación de la aplicación del caso a la norma, no pueden por ello sufrir un exceso de fuentes de generalización de las definiciones y menos aún contradicciones entre ellas que lleven a que dos interpretaciones contrapuestas puedan sustentarse con diferentes argumentos normativos. Se puede entrar aquí en el ámbito de los efectos antijurídicos producidos por el exceso y la concurrencia de normas que pueden resolverse en la jurisdicción constitucional u ordinaria aplicando los principios de jerarquía y competencia dentro de los subsistemas jurídicos, ya sean internos o externos del Derecho internacional, sin embargo dichos efectos vienen a ser sintomáticos de un fenómeno generalizado ante la profusión normativa ${ }^{21}$.

${ }^{20}$ En esta óptica, a efectos de la investigación, la doctrina no sólo la constituye la jurisprudencia como interpretación formal vinculante en la aplicación de las normas, sino la obra científica basada en el principio probado de conocimiento y autoridad de los investigadores o tratadistas, cuya obra, o en ocasiones informes y dictámenes, gozan de reconocimiento en el campo de la investigación o el asesoramiento juridico.

${ }^{21}$ Vid. ReQueJo PAgES, Juan Luis. «Conjunción de sistemas normativos y reordenación del sistema de fuentes» en Revista de Estudios Políticos, n. 90, Octubre-Diciembre, 1995. págs. 113-128. 
La normativa legislativa, que pertenece al tipo de generalización, o la reglamentaria, que sirve a la especificación de los casos de aplicación, tienden a crecer sin una detenida consideración de su adecuación, o bien por la naturaleza de la materia tratada que requiere estabilidad normativa y acuerdo consociacional, o por la simple irrelevancia del adendo que una norma hace a la legislación y doctrina existente en su aplicación a las actuaciones públicas, o porque las especificaciones dadas sobre limitan un adecuado grado de concreción de la necesidad general o accidental de la norma. En tales extremos acudimos a un desiderátum de inseguridad jurídica. En este sentido, en el ámbito del Derecho administrativo son continuas las peticiones de desarrollo legislativo y reglamentario a menudo más allá de lo que la ciencia y técnica jurídica están en condiciones de regular ${ }^{22}$.

La necesaria transparencia del sistema normativo, que es presupuesto básico de la certeza del Derecho, se ve suplantada por su creciente opacidad: el Derecho positivo resulta inaccesible incluso para los propios especialistas, resquebrajando el valor de la seguridad jurídica con la permanencia de normas inoperantes por falta de información, situación que puede ser calificada como de «decadencia de la seguridad jurídica ${ }^{23}$. Por este motivo la técnica legislativa ha de encargarse no sólo de los aspectos meramente formales, sino de la calidad material en la elaboración de leyes susceptibles de ser cumplidas ${ }^{24}$.

${ }^{22}$ Las medidas desreguladoras invocan el principio de simplificación normativa, guiadas por estrategias sectoriales, como es el caso de Ley 20/2013, de 9 de diciembre, de garantía de la unidad de mercado y el Plan de Racionalización Normativa dentro del Programa Nacional de Reformas 2013. Se trata de revisar todas las normas estatales y autonómicas para garantizar el principio político de Unidad de Mercado. Sin embargo, para ello se recurre a una nueva norma legislativa estatal situada en la diana de la invasión de competencias autonómicas de ámbito constitucional que la Generalitat de Catalunya se plantea recurrir y declara que perjudica la competitividad empresarial. Con independencia del resultado jurisdiccional, la simplificación normativa no puede ser incoherente con un principio superior del ordenamiento jurídico. GOVERN DE LA GENERALITAT DE CATALUNYA. «El Govern demana un informe al Consell de Garanties Estatutàries sobre la Llei de garantia d'unitat de mercat» en Acords de Govern 14 de gener de 2014. págs. 10-11. <http://www.govern.cat/ pres_gov/AppJava/govern/govern/consell-executiu/acords-govern/acordgovern-4221. html> (consultado el 16-01-2014).

${ }^{23}$ PÉrez LuÑo, Antonio Enrique. «La seguridad jurídica» en Boletín de la Facultad de Derecho, UNED, n. 15, 2000. pág. 36.

${ }^{24}$ «Ha sido en el terreno de los hechos desde donde, sin resquicio a duda, se han perpetrado los ataques más implacables al valor jurídico de la seguridad [...]. La inflación normativa se ha visto acompañada del grave menoscabo de la propia estructura formal de las normas legales. La certeza del Derecho, en cuanto a la posibilidad real de sus destinatarios de conocer y cumplir sus prescripciones, se ha resentido del aluvión normativo y de su continua modificación, pero en grado no menor de la pro- 
Ahondando en las raíces materiales de este proceso de sobredimensionamiento legislativo, Ángeles Galiana Saura sitúa estas características dentro del Estado social o del bienestar. Todo ello queda enmarcado en un sistema que rompe el principio estricto de la separación de poderes, en el que poderes y funciones se entremezclan, y el poder ejecutivo cobra un papel preponderante en la legislación a través del ejercicio de la potestad reglamentaria, los proyectos y las autorizaciones legislativas que recogen directamente las necesidades cotidianas o motivaciones técnicas ${ }^{25}$.

«Está claro, por tanto, que el Estado Social de Derecho ha producido un cambio profundo en la actividad legislativa. Las diversas formas de incidencia legislativa sobre la economía y el mercado de trabajo y la presencia creciente de los órganos administrativos en diferentes sectores de la sociedad civil remiten a una nueva configuración del instrumento legislativo, de manera que la Ley contemporánea incorpora cada vez más medidas tendentes a regular las relaciones socio-económicas de sus destinatarios, con lo que asume poco a poco un decidido «carácter contractual», y se transforma, así, de general y abstracta, en individual y concreta» $^{26}$.

Es notable cómo se traza en esta ubicación del Estado social el antecedente que asienta la evolución y continuidad del Estado, pues el fortalecimiento del ejecutivo no es sino una tendencia histórica que en el Estado social se refuerza, aunque germina en los propios orígenes del Estado liberal. También la mencionada mezcla entre funcio-

lijidad, complejidad y equivocidad de lenguaje en el que se expresaba las disposiciones legales«. (Ibid. pág. 35).

${ }^{25}$ Vid. Galiana Saura, Ángeles. La legislación en el Estado de Derecho. Madrid, Dykinson, 2003. págs. 73-78. En esta obra se propugna la disciplina de la Metódica legislativa que junto a la Técnica legislativa forma parte de la Ciencia de la legislación. Esta se ocupa de la producción de las leyes o la legislación como actividad, cuyo propósito, a diferencia de la interpretación y aplicación de los textos legales, consiste en analizar la forma y el contenido de las leyes con «el propósito de encontrar los criterios de una legislación racional». También queda señalado por Pérez Luño, el origen de la «inflación normativa» en el Estado del bienestar. «El tránsito del Estado liberal al Estado social de Derecho ha comportado una presencia creciente de los órganos administrativos en diferentes sectores de la sociedad civil. Pero la satisfacción de esa procura existencial (Daseinvorsorge) a través de las consiguientes prestaciones y servicios públicos, que distingue al Welfare State ha tenido su coste en términos dé erosión del principio de legalidad. La multiplicación de intervenciones normativas del Estado se realiza, las más de las veces, por vía de medidas o providencias administrativas. Con ello, se disuelve la tradicional división de funciones entre el legislativo y el ejecutivo: las clásicas leyes formales (Rechtsgesetze) se han visto, de forma paulatina, suplantadas por leyes medida (Massnahmegesetze)». (PÉREz LuÑo, Antonio Enrique. «La seguridad jurídica»... Op. Cit. pág. 35)

${ }^{26} \mathrm{Vid}$. Galiana SAura, Ángeles. "La actividad legislativa en el Estado social de Derecho» en Cuadernos Electrónicos de Filosofía del Derecho, n. 2, Universidad Rovira i Virgili. 1999. <http://www.uv.es/cefd/2/galiana.html> (consultado el 19-02-2014). 
nes y poderes recuerdan la vieja teoría formal-sustancial que asentó la doctrina del Derecho administrativo desde la pandectística y la escuela histórica que forjaron su dogmática ${ }^{27}$. Sin embargo, es hacia adelante, interpretando la continuidad del Estado social en las raíces de su reforma privatizadora y neoliberal, como conviene seguir la lectura de los problemas normativos en la modernización administrativa y la nueva gestión pública.

\section{I.2.B. Tecnificación normativa y garantías jurídicas}

De acuerdo al análisis recogido por Joan Prats, la OCDE reconoce que la primera etapa desregularizadora desde finales de los 70 a los años 80 del siglo XX fracasa en su intento de liberalizar y combatir la inflación y confusión normativa mediante codificaciones y simplificaciones de las regulaciones. Ante esta incapacidad, en una segunda fase de fines de los 80 a la década de los 90, se fija en el Consejo de la OCDE de 1985 el objetivo de la calidad de las regulaciones mediante la introducción de pasos extrajurídicos para la información, la consulta y la participación públicas. Sin embargo, la tecnificación del mejoramiento regulatorio, que algunos países aspiran o pasan a convertir en principios jurídicos para la elaboración de normas legislativas, pierde la perspectiva del sistema en su conjunto por su aplicación a cada nueva regulación individual. Por último, se pasa a una tercera fase que trata de crear la capacidad institucional para dirigir el sistema regulador, estructura que se agrega a la anterior ante la falta de competencias de estas nuevas funciones en las instituciones vigentes que se dedicaban a las regulaciones singulares ${ }^{28}$.

El sistema regulador propuesto finalmente por la OCDE y seguido por numerosos Estados en diferentes formas y grados, no es sino un epítome de las reformas propuestas ante la gran demanda de regulación que existe más allá de las fronteras del Estado social, sin desdeñar su origen en él y aún su vigencia en los Estados liberal-democráticos de la Europa continental. En realidad la demanda y disgregación normativa surgida en el apogeo regulador del Estado social no hace sino continuar y agravarse ante "los caracteres de nuestra sociedad, condicionada por una amplia diversificación de grupos y estratos sociales que participan en el mercado de las leyes. Dichos grupos dan lugar a una acentuada diferenciación de tratamientos normativos, sea como implicación empírica del principio de

\footnotetext{
${ }^{27}$ Véase el epígrafe 2.3.3 de esta investigación.

${ }^{28}$ Prats Catalá, Joan. «Las transformaciones... » Op. Cit. págs. 76-80.
} 
igualdad del llamado Estado social (para cada situación una disciplina adecuada a sus particularidades), sea como consecuencia de la presión que los intereses corporativos ejercen sobre el legislador ${ }^{29}$. A esta naturaleza cuasi contractual de la actividad normativa siguen, tras los procesos privatizadores, las efectivas demandas reguladoras que la liberalización de los mercados arrastran como un escenario que marca las reglas de protección de la actividad privada o simple vigilancia de su competencia por el árbitro público ${ }^{30}$.

Por otro lado la carencia de referentes jurídicos y jurídico-administrativos situarían en el centro de la ejecutoria pública la subjetividad y discrecionalidad de sus actuaciones, sin que un debido criterio técnico, a menudo sujeto a la interpretación disciplinar anteriormente enunciada, asegure una formación de voluntad acorde con los intereses generales o los principios democráticos que deben presidirla. Es la práctica la que revela cómo en muchos casos, debidamente sustentado el marco jurídico, es el marco técnico el que dentro de él puede y debe ostentar plena capacidad de acción para la toma de decisiones o ejecución de los actos y ordenación de las disposiciones que afectan a la propia actuación pública, todo ello sin que esto suponga la exención del juicio jurídico y el amparo del Derecho ${ }^{31}$.

Por lo tanto, se puede sostener que si bien es acertado considerar al Estado social en el sentido constitucional como la forma de régimen político que da lugar, por las múltiples evidencias analizadas, a la hipertrofia de la legislación positiva y los excesos reglamentistas que causan la quiebra del principio de seguridad jurídica, no parece menos cierto que dicha tendencia se ve acentuada por la reglamentación que introduce la nueva gestión pública y la modernización administrativa. En este último caso con la decidida proliferación de normas de carácter técnico extrajurídico, que muestran, entre otras, la función del Derecho comunitario ante el ordenamiento jurídico-económico liberalizador, las normas homologadoras que garantizan la

${ }^{29}$ Zagrebelsky, G. El Derecho dúctil. Ley, derechos, justicia. Trotta, Madrid, 1995, pág. 37.

${ }^{30}$ Como expone el propio Joan Prats «Dentro de la propia agenda neoliberal, aunque la tendencia general fue la desregulación, nunca se renunció a construir una capacidad reguladora del Estado que remediara los innegables fallos del mercado, sin dejar de considerar en ningún caso lo que la economía de la elección pública ha llamado los «fallos del Estado». Prats CaTALÁ, Joan. «Las transformaciones de las administraciones públicas de nuestro tiempo» en Estudios para la Reforma de la Administración Pública (Dtor. Fernando Sainz Moreno). Madrid, INAP, 2004. pág. 71.

${ }^{31}$ Como se ha visto en otras partes de la investigación la figura de la discrecionalidad técnica también aparece vinculada a ciertos excesos de la seguridad jurídica. Vid. Morell Ocaña, Luis. Curso... loc.cit. 
libre competencia en su espacio económico interno, o los estándares de producción de sus mecanismos proteccionistas en el orden externo. Por otra parte, la privatización de la gestión pública obliga a sustituir el intervencionismo anterior por una regulación mínima que trata de garantizar la igualdad y neutralidad de los poderes públicos en el libre acceso del ámbito privado a la transferencia patrimonial y gestión de servicios básicos de infraestructura, de interés público, o titularidad competencial pública, para asegurar la continuidad de estos servicios en el régimen de explotación privada ${ }^{32}$.

\section{I.2.C. Hacia nuevos planteamientos}

Esta realidad presenta una importante consecuencia en la valoración de la figura jurídica que soporta la diversidad y especialización normativa recogida por el Derecho administrativo, que Enrique Linde agrupa en su Parte Especial, de la que manifiesta que: «La extensión e intensidad del intervencionismo administrativo en la sociedad impide un análisis exhaustivo del mismo ${ }^{33}$. No se trata en líneas generales, desde las premisas de esta investigación, de intervencionismo, sino fundamentalmente de regulación, que acompaña a los procesos privatizadores, o en su intensa relación dialéctica por mostrar una contradicción aparente, con los procesos liberalizadores, es decir desregularizados stricto sensu, que sin embargo demandan la protección y el ordenamiento necesario para garantizar la libre competencia o la seguridad jurídica particularizada que requieren los nuevos mercados creados en esos procesos. Si se trata de una legislación reguladora ex-ante que puede presentar una labor codificadora ex-post, tal vez su intensidad impide, como señala Linde, el verdadero esfuerzo doctrinal al que se enfrenta el marco jurídico administrativo para la objetivación y síntesis que constituye el reto ante el cual dicho marco no puede absorber, en los términos prácticos que se persiguen, la ingente reglamentación técnica que preside la gestión pública de la modernización administrativa. En suma, el reto de facilitar una adecuada

${ }^{32}$ «Las industrias de servicios en general, incluyendo la banca y los servicios financieros, seguros, servicios profesionales, pensiones, sanidad y servicios públicos domiciliarios, han estado sometidas en los últimos años a un generalizado proceso de liberalización. Este proceso ha sido especialmente intenso en el caso de las industrias de servicios públicos de red (public utilities): telecomunicaciones, electricidad, gas, agua, transporte y servicios postales». (Costas, Antón. «Regulación...»Op. Cit. pág. 9).

${ }^{33}$ Linde Paniagua, Enrique. «Introducción» en Parte especial del Derecho administrativo. La intervención de la Administración en la sociedad, (coord. Enrique Linde Paniagua). Madrid, Colex, 2007. págs. 41-42. 
comprensión y aplicación del Estado de Derecho bajo el principio rector e ineludible de la seguridad jurídica.

Por todo ello, tras la crisis del Estado del bienestar aparece una introducción de las políticas públicas en la gestión pública, es decir, definición y ejecución de objetivos premeditados por el Gobierno para intervenir en la organización de la Administración. Introducción que debe servirse de fuentes legitimadoras en las que el ordenamiento jurídico, en la aplicación de los principios constitucionales y las políticas de gestión pública, trata de obtener una Administración como brazo ejecutor de los poderes públicos al servicio de los ciudadanos. Servicio cuyo principal fin es ordenar la realidad social y procurar la «vida buena» de acuerdo con las bases de derechos y libertades que el Estado para ese fin ha establecido en su ordenamiento jurídico presidido por el deber de cumplimiento de la legalidad ${ }^{34}$.

Desde el planteamiento que afecta a esta investigación la modernización de las administraciones públicas es consecuencia de los cambios de la sociedad y de las transformaciones que en ella operan. En este sentido las políticas de gestión pública inciden en nuevas técnicas de gestión que pueden, dentro del citado ámbito público, acometer programas y acciones que actúan sobre nuevos fenómenos sociales y requieren nuevas formas de procurar los bienes públicos ${ }^{35}$. Por otra parte los instrumentos jurídicos son el soporte de la acción que asegura una finalidad basada en el interés público, pero no siempre su cumplimiento efectivo. Por ello se tratan de implantar elementos que perfeccionan la equidad práctica del sistema jurídico y otros medios de gestión que aseguran la eficacia de los programas, las accio-

${ }^{34}$ Vid. Aristóteles. Política. Madrid, Alianza, edición de 2000, versión del griego de Carlos García Gual y Aurelio Pérez Jiménez. pág. 269. Se vuelve a invocar el principio rector de la misión del Estado en la tradición occidental que arranca del Estagirita: «Es misión del legislador competente considerar en una ciudad, casta humana, o cualquier otro tipo de comunidad, como pueden alcanzar una vida buena y la felicidad que les está permitida».

${ }^{35}$ Prats Catalá, Joan. «Las transformaciones... » Op. Cit. pág.34. Sobre los nuevos desafíos que la globalización plantea a la Administración el autor expone como altera decisivamente las tareas tradicionales y obliga a plantear otras nuevas. "La procura de bienes públicos (servicios uti universitatis) objeto de la tradicional función de policía, se plantea de forma completamente diferente...no puede hacerse sino de modo parcial y subordinado mediante las intervenciones tradicionales de reglamentación inspección y sanción. Las tareas fundamentales hoy son otras: creación de observatorios, sistemas de información y conocimiento, sistemas de alerta temprana...Incluso intervenciones clásicas como las regulaciones cambian de sentido. Pues al darse a nivel supranacional, o hasta global, requieren capacidades para influir efectivamente en la regulación -no siempre formal- en que la globalización existe.» 
nes y los servicios que despliegan sobre ese sustrato legal la ejecución del Gobierno y la Administración ${ }^{36}$.

El ciudadano como sujeto del sistema político y el usuario de la Administración como objeto al que se dirigen sus prestaciones públicas presupone la seguridad y los controles necesarios que aseguran la equidad del ejercicio del poder en las actuaciones de ambos entes. Las garantías públicas que demanda el ciudadano son la sustanciación de los derechos y la facilitación de los servicios que sólo pueden satisfacer los poderes públicos. Por lo tanto, podría afirmarse que aparece un nuevo marco material del Estado de Derecho basado en los medios de gestión que aseguran la eficacia en la satisfacción de las necesidades de los ciudadanos. Marco material que por las premisas expuestas sigue llamado a encontrar una base jurídica eficaz y proporcionada para conjugar los intereses generales y particulares.

\section{ADAPTACIÓN DE LAS RELACIONES JURÍDICAS EN LA ORGANIZACIÓN Y GESTIÓN DE LOS SERVICIOS PÚBLICOS}

Las relaciones jurídicas que impone la modernización administrativa exigen una adaptación a nuevas formas de organización que responda a dos importantes condicionantes: el cambio en las relaciones de la Administración con los ciudadanos y las consecuencias de la descentralización organizativa en el mantenimiento de la responsabilidad pública.

El primero plantea la subordinación de los poderes públicos a los derechos subjetivos y la demanda de los ciudadanos en el nuevo modelo de funcionamiento. La transformación respecto a las funciones tradicionales de la Administración no abandona el marco político del Estado liberal, pero si exige nuevas relaciones jurídicas entre aquella y los ciudadanos portadores de dichos derechos subjetivos y demandas de servicios que se deben garantizar ya sea formal o materialmente. Esta exigencia modifica la gestión por procedimientos jurídico administrativos por la gestión con métodos técnicos acomodados en su aplicación a un marco jurídico privado que incluye su extensión a una directa gestión privada, libre de la tutela de garantías sobre los

\footnotetext{
${ }^{36}$ Las normas también exigen no sólo una fundamentación suficiente sino la consideración de los diversos intereses y la posibilidad de deliberación informada entre todos ellos bajo el concepto de «calidad de las normas», "no sólo en términos de rigor técnico y seguridad jurídica, sino también de legitimidad democrática, medida a su vez por las posibilidades de información y participación deliberativa efectivamente otorgadas a los diversos grupos de interés concernidos por la norma». (Ibid. pág. 34-35).
} 
principios de legalidad, igualdad, objetividad y las cláusulas social y democrática ${ }^{37}$.

El segundo condicionante lo determina el modelo organizativo descentralizado que invoca las mismas exigencias de orientación de la actividad administrativa, en tanto al ciudadano, al usuario y al cliente de la Administración. Su consecuencia afecta a otro principio jurídico fundamental que define la personificación administrativa como sujeto de Derecho en la función de la responsabilidad pública. La descarga de la responsabilidad asume la pérdida de garantías jurídicas como un mecanismo de agilización de la actividad administrativa en la particularización y privatización de sus ámbitos de actuación.

Ambos condicionantes suponen los retos de las relaciones jurídicas de la organización administrativa que se tratan de examinar.

\section{II.1 Condiciones jurídicas de las relaciones entre Administración y ciudadanos en la organización}

\section{II.1.A. Caracteres de las relaciones jurídicas entre poderes públicos y ciudadanos}

En el Estado liberal clásico, la relación entre la Administración y los ciudadanos sostenía su igualdad jurídica ante los poderes públicos por el principio de legalidad ${ }^{38}$. Sin embargo, dicho principio no evitaba la limitación del acceso tanto al sistema político, a través del derecho de sufragio y representación censitaria, como a la protección subjetiva, que los fundamentos jurídicos y consecuentes actos administrativos propiciaban, dando lugar a una especie de igualdad restringida $^{39}$. Se puede entender que se producía así un distanciamiento entre la formulación del principio jurídico y la eficacia con la que ese

${ }^{37}$ No se hace referencia a un uso instrumental del Derecho privado para realizar ciertos actos que requieren normas civiles de relación, (enajenaciones, arrendamientos entre otras) si no en la propia actividad y organización administrativa en el ejercicio de sus funciones propias.

${ }^{38}$ El principio inspirador se encuentra en el artículo VI de la Declaración Universal de los Derechos del Hombre y del Ciudadano aprobado por la Asamblea Nacional Constituyente francesa el 26 de agosto de 1789. Más adelante, en el artículo XV se subordina a la Administración por el derecho de la sociedad a pedirle cuentas.

39 «De algún modo la Revolución Francesa no deja de ser sino un mero cambio en la titularidad del poder que supondrá la marginación de las técnicas y organizaciones incompatibles con sus intereses [de la burguesía] y la emergencia de otras técnicas, organizaciones y principios». (Linde Paniagua, Enrique. Fundamentos del Derecho administrativo. Del Derecho del poder al Derecho de los ciudadanos. Madrid, Colex, 2009. pág. 46). 
principio se materializaba en la norma positiva. En el Derecho público liberal determinados principios constitucionales no quedaban plenamente garantizados, pero tampoco provocaban un indiferente jurídico, de forma que en el desarrollo del Derecho positivo se iban creando normas con regulaciones específicas que, casi siempre ante las demandas sociales y sectoriales, delimitaban los principios formales al establecer las condiciones jurídicas materiales

Este fenómeno va dando lugar a la aparición de regímenes jurídicos especiales. Sirva de ejemplo, entre otros, el Derecho laboral, que desprende del Derecho civil la especialidad de las relaciones contractuales en las que los objetos de transacción incluían la prestación personal del trabajo. En estas circunstancias el Derecho público proporcionaba las garantías de igualdad que las libres condiciones contractuales no podían propiciar y, por lo tanto, el Estado debía regular de manera estable. En general, la protección pública de los intereses sociales se inscribe en una categoría más amplia que relaciona el derecho público con el privado y provoca el carácter intrusivo del primero en el segundo, relación jurídica que se perfecciona cuando introduce la reciprocidad, Schmidt-Assmann lo destaca afirmando:

El ordenamiento jurídico privado es derecho estatal y expresión de su capacidad de configuración: los mecanismos de equilibrio del mercado, para ser manejables, deben desplegarse en forma jurídica, el contrato y la propiedad no sólo deben ser reconocidos, sino convertidos en instituciones jurídicas utilizables. [...] También el marco dispuesto por el legislador de Derecho privado establece formas de resolución de conflictos, y con ello persigue objetivos públicos. Éstos pueden ponerse de relieve con intensidad comparable a lo que acontece en el Derecho público, en aquellos ámbitos en los que el Derecho privado ha introducido regímenes de protección especial a favor de consumidores, vecinos, inquilinos o competidores $^{40}$.

El concepto de ciudadano se va formando históricamente en diferentes dimensiones. En primer lugar como sujeto de derechos políticos, cuyo origen formal o declarativo se desarrolla en los inicios de la Revolución Francesa y Americana, en el Estado liberal doctrinario recaerá en el contribuyente y sólo se extiende de forma efectiva en las constituciones liberales democráticas desde fines del siglo XIX. En la perspectiva de su relación con la Administración, la dimensión del ciudadano como usuario de los servicios públicos emerge dentro del Estado social y evoluciona en la estrategia del cliente bajo el modelo privatista de la nueva gestión pública, figura que conecta con

${ }^{40} \mathrm{Vid}$. Schmidt-Assmann, Eberhard. Teoría general del Derecho administrativo como sistema. Madrid, Marcial Pons-INAP, 2003. págs. 294-295. 
la concepción competitiva privada de la actividad administrativa pública $^{41}$. En estas dimensiones es posible encontrar los matices respecto a la eficacia jurídica de los derechos del ciudadano extraídos de diferentes categorías establecidas por Schmidt-Assmann:

a) El usuario que se relaciona con la Administración se enfrenta a unos intereses generales inespecíficos con un amplio uso de las prerrogativas administrativas. Amparados en los derechos fundamentales que otorgan la legitimación a los poderes públicos, los derechos subjetivos concretan y precisan la acción individual y la tutela jurídica del usuario en sus relaciones con la Administración ${ }^{42}$.

b) El cliente propugna la individualidad, que en cierto modo retoma ciertos rasgos del Estado liberal primigenio al supeditar la aplicación de las garantías y derechos a la capacidad de representación de los intereses particulares y sectoriales. Así, en el nuevo modelo de relación pública, el cliente toma, al menos, dos aspectos: como ciudadano, donde la prestación administrativa es concebida como producto dirigido a éste; como figura sectorizada que relaciona a las entidades supervisoras de servicios públicos ya desregulados o privatizados con sus redes clientelares de usuarios y empresas prestadoras ${ }^{43}$.

${ }^{41}$ La orientación al cliente en el sector público tuvo como gran publicista y posible pionero a Al Gore en los informes del NPR, destacando los Costumer Service Reports y los «Putting Customers First: Standards for Serving the American People» (October 1994), "Putting Customers First '95: Standards for Serving the American People» (October 1995) y «Putting Customers First '97: Standards for Serving the American People» (October 1997). Entre las repercusiones de este concepto en España, la Comunidad de Castilla La Mancha emprende el Plan de Modernización, aprobado por Acuerdo del Consejo de Gobierno el 30 de marzo de 1993 al amparo de la Inspección General de Servicios, en este contexto y bajo el impulso del enfoque de la calidad aparece la «estrategia del cliente» en diversos servicios públicos, como La Universidad, que llega a recoger el objetivo de «trasladar a las entidades públicas prestadoras, con las debidas adaptaciones, técnicas gerenciales propias del sector privado [...] Una de las estrategias, entre otras varias, $[\ldots]$ consiste en orientar su actividad al 'cliente'»Vid. Collado YurRita, Miguel Ángel y MarTínez TiRADo, Juan Francisco. La inspección de servicios en el ámbito de la Universidad. Universidad de Castilla la Mancha, 2000. pág. 23.

${ }^{42}$ Schmidt-Assmann sitúa los derechos subjetivos en la cúspide de la subordinación de los poderes públicos que se someten por mandato constitucional y con carácter preferente a los derechos fundamentales, con origen en la evolución del Derecho tras la segunda posguerra. Schmidt-Assmann, Eberhard. Teoría general... Op. Cit. págs. 94-95.

${ }^{43} \mathrm{Vid}$. Ibid. pág. 32 respecto al cliente-ciudadano y pág. 257 en las relaciones clientelares de regulación del mercado. 
c) En una nueva dimensión jurídica el ciudadano puede identificarse como agente de cumplimiento de las normas. Surgida en la habilitación que los ciudadanos reciben en el Derecho comunitario para exigir el cumplimiento de trasposición de estas normas en sus respectivos Estados por la defensa de su propio interés, por ejemplo en el ámbito medio-ambiental entre otros $^{44}$.

\section{II.1.B. Regulaciones jurídicas y técnicas en la organización de los servicios públicos}

En el desarrollo jurídico administrativo ninguno de los sustratos establecidos históricamente se pierde, si no que en cada uno de ellos aparece un nuevo subsistema de relaciones, sin que esto evite la posible revisión de determinados principios de los sustratos anteriores, que más adelante pueden volverse a reponer. Así, sobre la cláusula social se amplían las modalidades de las relaciones jurídicas prestacionales entre la Administración y los ciudadanos, pero la igualdad formal no puede incorporar a los sectores que carecen de capacidad para establecer la relación, lo que ocasiona un ejercicio restringido de derechos específicos a las personas que cumplen las condiciones para recibir dichas prestaciones (económicas, políticas o sociales entre otras).

Por otra parte, las políticas públicas, cuya libertad de elección se legitima por el principio del pluralismo de la cláusula democrática, se sirven también, como en el Estado liberal clásico, de aquellos instrumentos formales en los que aparece una cuestión material que puede favorecer la discrecionalidad política y la desigualdad jurídica. Esta situación se resuelve en la institución de la primacía de los intereses generales mediante la arrogación de poderes exorbitantes a las actuaciones públicas. Ante ello, lo que en un derecho formal o material de índole administrativa se garantiza jurídicamente, no es extensible a la actuación prestacional pública si no incorpora la disposición de la ejecución material del derecho. Por lo tanto, asegurar la efectiva aplicación de las regulaciones jurídicas sobre obligaciones públicas parece exigir una ordenación concreta que garantice las pre-

44 «Aunque también para el Derecho administrativo comunitario la posición jurídica del ciudadano de la Unión constituye un elemento clave, sin embargo ésta responde a una inspiración menos centrada en la protección del individuo. En realidad, esa posición jurídica individual parece confundirse o amalgamarse con la defensa de la legalidad objetiva, con la intención de asegurar la efectividad del Derecho». (Ibid. pág. 45). 
visiones materiales para la ejecución de las normas y resoluciones administrativas de los derechos reconocidos al ciudadano. Garantía que sólo parece posible establecer con procedimientos técnicos, que por el carácter de la materia regulada, en gran parte de los casos de la actividad prestacional, tienden a ser extrajurídicos ${ }^{45}$.

Si la aplicación del Derecho que delimita las relaciones entre la Administración y los ciudadanos especifica la forma especial en la tutela de los intereses generales que ostenta, el mandato constitucional del artículo 53.3 CE de ejecutar de forma efectiva los derechos y obligaciones contraídos entre los poderes públicos y ciudadanos, difícilmente puede eludir una interpretación en la actuación jurídica y administrativa cuya eficacia material debe sustanciarse tomando en cuenta la situación real de los sujetos ${ }^{46}$. Es aquí donde las posibles limitaciones que lleva la aplicación de la técnica jurídica se ha llegado a ver, al necesitar siempre un procedimiento garantizador formal, como un obstáculo en tanto instrumento rector de la actividad pública ante los retos de orientación al ciudadano, eficacia y eficiencia que la modernización impone a los objetivos de la Administración en la provisión de los servicios públicos.

A partir de aquí, el vacío lo trata de ocupar un ámbito técnico basado, incluso con exclusividad, en la gestión política, económica y las teorías funcionales de organización y dirección ejecutiva, que fijan su

${ }^{45}$ Se pueden destacar las políticas sociales del área latinoamericana, como el caso de México, donde coexiste la imperiosa necesidad de ejecutar prestaciones asistenciales bajo el diseño programático de un Estado del Bienestar, con técnicas de gestión pública propias del área angloamericana introducidas por el espacio geopolítico compartido. Vid. CARDOzo, Myriam. «Organización y métodos alternativos en la evaluación de políticas y programas sociales. La experiencia consolidada y la emergente en el caso de México» en GAPP, n. 5, enero-junio 2011, págs. 43-59. En el caso desarrollado se muestra la contraposición entre el modelo positivista, de origen estadounidense, y el constructivista, de tipo europeo, en el primero predominan un enfoque objetivo y cuantitativo de la evaluación prestacional, mientras que en el segundo se ponderan los métodos cualitativos que parten de la dimensión organizativa, política y jurídica de la Administración en el proceso evaluador.

${ }_{46}$ Sentencia n. 3/1983 de Tribunal Constitucional, Pleno, 25 de Enero de 1983. Informa de la doctrina sobre la inconstitucionalidad de la restricción de los derechos fundamentales no justificados por la efectividad de otro derecho fundamental y libertad pública. La interpretación de esta doctrina debe admitir al mandato general de la norma si no incumple la hipótesis por la que puede aplicarse restrictivamente en un caso concreto sin contradicción entre derechos fundamentales, en cuyo caso se anularía ese mandato general. Cuánto más resulta aplicable al acto o resolución administrativa que obliga a interpretar la norma de acuerdo a la proporcionalidad que aconseja la protección del derecho si no lesiona otros y evitar su denegación ante un supuesto concreto por una interpretación limitadora de la norma. STC 3/1983 cit. en Vid. Santamaría Pastor, Juan Alfonso. Principios de Derecho Administrativo General. v. I. Madrid, Iustel, Portal Derecho, S. A., 2004. 1. a ed. pág.102. 
objeto en las políticas y la gestión públicas, así como la aplicación de los principios de descentralización y optimización en la gestión económica y presupuestaria. Sin desdeñar el avance que abren estos campos en la transformación y modernización de la Administración, lo cierto es que su implantación sin un marco jurídico adaptado a los fines públicos, tiende a incurrir en contradicciones axiológicas con el interés público insalvables en el desempeño de su actividad.

Ante ello, la organización del servicio público con técnicas privatistas puede someter al marco jurídico a presiones de introducción del Derecho privado. Esto quiere decir, y es importante subrayarlo, que la ordenación de las relaciones desiguales entre la Administración y el ciudadano corren el riesgo de perder eficacia jurídica ante la aparición de criterios por las que dichas relaciones se establecen libremente ${ }^{47}$. En el plano organizativo significa que pueden aparecer órganos cuyo diseño sirve a fines sectoriales que no encajan adecuadamente en el constructo de los intereses generales, al basarse en una libre elección del contrato de servicio que establece una relación altamente singularizada y desigual de relación clientelar por parte de los poderes públicos ${ }^{48}$. Pero, por otra parte, el mismo principio democrático obliga a considerar el carácter plural del ámbito privado no sólo en la elección del poder legislativo y la designación del ejecutivo, sino en la propia acción de éste último a través de la Administración Pública en cuanto a su estructura y gestión. En cierto modo parece que en la evolución del concepto de ciudadanía la Administración adopta unos principios privatistas a los que se acomoda

${ }^{47}$ Entre otros rasgos de la pérdida de la eficacia jurídica se puede señalar la capacidad jurídica de la Administración y sus unidades inferiores en la relación con el ciudadano en el concepto de la personalidad jurídica parcial: «El actual Derecho de la organización no da demasiada importancia a las demás repercusiones de esta figura jurídica, que sin embargo son muy relevantes. La idea del carácter unitario de la capacidad jurídica se deriva de las exigencias y condicionantes del Derecho Privado». La escasa delimitación de la personalidad jurídica que sólo se otorga en su plenitud a las Administraciones, no se corresponde con la capacidad de actuación de las entidades administrativas creadas por la descentralización en la gestión, permitiendo así un foco de inseguridad e ineficacia jurídica (ScHMIDT-AssmanN, Eberhard. Teoría general... Op. Cit. pág. 253)

${ }^{48}$ Schmidt-Assmann expresa el carácter externo de las formas jurídicas de la organización respecto al contenido interno de la estructura de los órganos de la Administración: «Estas formas jurídicas [de la organización administrativa referida a los conceptos de cargo, órgano, corporación, institución,...] garantizan la capacidad de de actuación de una determinada unidad organizativa con el fin de intervenir en el tráfico jurídico, así como su posición jurídica en relación con otras unidades de la Administración, incluida la posibilidad de defender judicialmente esa posición jurídica [...] sin embargo resulta poco determinante del contenido o estructura interna de la unidad organizativa de que se trate». (Ibid. pág. 253). 
mal el ámbito jurídico administrativo produciendo, en suma, un desajuste con los principios del Derecho público a los que está llamado a proteger y desarrollar ${ }^{49}$. Si las formas jurídicas de la organización no representan las técnicas necesarias para ejecutar el programa prestacional o la transformación de las relaciones de ejercicio del poder que la redefinición del papel del ciudadano conlleva, parece probable que aquellas se desarrollen sin la protección jurídica que el ejercicio público demanda de sus principios de legalidad, igualdad y democrático. Pueden, por ende, resultar afectados la neutralidad y el control de la actividad de la gestión pública dada la imprecisa delimitación de la «independencia o subordinación de unas unidades administrativas respecto a otras» ${ }^{50}$.

II.1.C. Cuestiones jurídico organizativas de la demanda subjetiva de servicios públicos

En el plano subjetivo resultante los ciudadanos demandan los servicios públicos bajo una perspectiva en la que se agrupan diferentes formas de satisfacer desde los poderes públicos sus necesidades, dicho de otro modo, la demanda subjetiva se adapta a la oferta pública sin que se establezcan otros vehículos jurídicamente reconocidos que los que en cauces constitucionales del artículo 128.2 CE establezca el poder ejecutivo o legislativo ${ }^{51}$. Dichas formas de oferta pueden ser sucintamente clasificadas del siguiente modo:

a) La protección de los derechos fundamentales y la aplicación de garantías en el cumplimiento de la legalidad en condiciones de igualdad en el acceso a la información y en la ejecución de las actuaciones jurídicas y administrativas (Cap. II CE $)^{52}$.

49 «En principio la expresión o noción de huida del Derecho administrativo aparece ligada a la utilización del Derecho privado por parte de entes o sujetos que cumplen funciones administrativas. Como aquél es el ordenamiento previsto para la regulación en estos casos, tal huida conducirá con mucha seguridad a una evasión o fuga, en general, del Estado de Derecho». (González-Varas, Santiago. El Derecho Administrativo Privado. Madrid, Editorial Montecorvo, 1996. pág.122)

${ }^{50}$ Schmidt-Assmann, Eberhard. Teoría general... Op. Cit. pág. 253.

${ }^{51}$ Muñoz Machado vincula los límites del servicio público a una solución doctrinal antes que constitucional de acuerdo con la relación entre el artículo 128.2 sobre la reserva de los servicios esenciales y el artículo 38 que consagra la libertad de empresa. Vid. Muñoz Machado, Santiago. Servicio Público y Mercado. I Los fundamentos. Madrid, Civitas, 1998. págs. 116-118.

${ }^{52}$ Aparecen serias dudas en la vinculación de la Administración a la Ley a causa de su estructura organizativa debido a los intereses burocráticos. Dentro de la nueva escuela administrativista alemana Jens-Peter Schneider destaca las limitaciones de la burocracia para operar junto al marco jurídico administrativo en una posición verda- 
b) Los servicios públicos básicos que garanticen el desarrollo económico y productivo (arts. 31.2 y $38 \mathrm{CE}$ ), que van desde los bienes y las infraestructuras de utilidad pública -el abastecimiento eléctrico, de agua, las telecomunicaciones y los transportes, entre otros- hasta la gestión y regulación de los recursos financieros internos y externos: la gestión presupuestaria, el control de los mercados financieros, las inversiones públicas, o todas las formas de fomento y protección de la actividad económica, sean directas como las ayudas y subvenciones, o indirectas a través de los incentivos fiscales. En general estos servicios pueden ser traspasados o ejecutados en cooperación con el ámbito privado, ya sea en una estructura empresarial o a través de instituciones de interés público, administraciones locales, o entidades privadas, que son objeto para ello de una regulación administrativa.

c) Los derechos sociales de carácter universal reconocidos constitucionalmente como sustrato de los deberes públicos prestacionales, como la educación, la protección de la salud y los servicios sociales sectorizados por grupos de interés declarados objeto de protección pública, tales como, entre otros muy diversos, ancianos, discapacitados, jóvenes, infancia y mujer (Cap. III CE). En muchos de estos casos aparece la interesante figura de la discriminación positiva, basada en legislar bajo un principio de desigualdad jurídica ante ciertos casos de desigualdad material que por el bien superior de su protección reciben una interpretación favorable de los intereses generales.

deramente neutral, pues, en palabras de Schmidt-Assmann, ésta convive con sus propios intereses y dificultades para evaluar la información que obtiene y debe tratar, Schneider, como deudor de aquel, analiza las dificultades en el terreno de la cooperación entre las administraciones: Vid. ScHNEIDER, Jens-Peter. «Kooperative und konsensuale Formen administrativer Entscheidungsprozesse» en Jahrbuch für Neue Politische Ökionomie, n. 15, 1996. págs. 82-102. Como escenario destacado en este ámbito profundiza en un sentido Assmaniano, en las aportaciones de la Unión Administrativa Europea como unidad emanada de los Derechos fundamentales, con las aportaciones realizadas en el derecho al acceso a los documentos públicos, el trámite de audiencia, el derecho a un procedimiento debido todo ello en el seno del desarrollo de normas sectoriales y los obligados instrumentos de cooperación entre Estados, y ad intra, entre administraciones federales y mixtas en los casos de Alemania y España, que obligan a conciliar el concepto de jerarquía y cooperación de las organizaciones comunitarias y a determinar los vínculos sistemáticos entre una organización y actuación administrativa común y la existencia de diferentes formas en las administraciones nacionales. Vid. Velasco Caballero, Francisco, y SchneIder. Jens-Peter (coord.). La Unión Administrativa Europea. Ed. Marcial Pons, Madrid, 2008. 
Desde estas demandas ciudadanas hacia la Administración, se conforma un Derecho con diferentes normas especiales de carácter no sólo sectorial, si no también territorial, que invitan a una reelaboración de la sistematización jurídica que articule un Derecho común, por supraestatal en el caso de la Unión Europea, o un cuerpo jurídico que rehaga doctrinalmente los principios del Estado de Derecho, pues en todos los sectores de la organización administrativa aparecen fenómenos que no se ajustan a la dogmática tradicional ${ }^{53}$. También, en el proceso de modernización de la organización pública, a cada forma de cubrir la demanda de esas necesidades del ciudadano le corresponden diferentes instrumentos jurídicos de conformación institucional o de regulación de entidades privadas situadas en áreas de interés público, entre las cuales el objetivo de proveer eficazmente al ciudadano se viene transformando en el criterio rector de funcionamiento y gestión a riesgo de incurrir en un proceso de deslegitimación que acaba erosionando la dirección política de la Administración y la propia función del Estado. Se produce así una concurrencia de los medios de gestión técnicos necesarios para cubrir los objetivos políticos de la Administración Pública que relega a los instrumentos jurídicos y organizativos de responsabilidad pública para alcanzarlos ${ }^{54}$.

\section{II.2. Efectos de la responsabilidad administrativa en la descentralización de los servicios públicos}

\section{II.2.A. La descentralización y el ejercicio de la responsabilidad pública}

Sobre el concepto de descentralización y su definición en la división asumida por la doctrina administrativa clásica entre las categorías de descentralización y desconcentración pasamos a considerar esta última una clase de la primera. Considerando, por consiguiente, la descentralización en sentido amplio, se trata de un concepto organizativo de gran alcance sobre los aspectos funcionales y jurídicos de la ejecución de la actividad pública de la Administración.

${ }^{53}$ Vid. Schmidt-Assmann, Eberhard. Teoría general... Op. Cit. pág. 256.

${ }^{54}$ «La separación entre Estado y sociedad tiene por consecuencia un efecto contrario al esperado: la indiferenciación de la administración pública y las empresas privadas por lo que respecta a los modos de gestión y a la competitividad». (BAÑón, Rafael. «Los enfoques para el estudio de la administración pública: orígenes y tendencias actuales» en La nueva Administración Pública, (eds. R. Bañón Martínez y Ernesto Carrillo). Madrid, Alianza Universidad Textos, 1997. pág. 37). 
Desde la perspectiva histórica de la atomización de las actividades de la Administración se puede distinguir la forma que preside el Estado del Bienestar a través de su intervención en el sector productivo o industrial, y el nuevo paradigma que la NGP prosigue al aplicar esa descentralización al sustrato de la actividad administrativa, entendida como aquella que recoge: las funciones de autoridad pública, que incluyen la limitación de los derechos y la ejecución de las medidas regulatorias; las actividades administrativas de gestión interna, en referencia a la gestión económica, patrimonial, de los recursos humanos, de los medios técnicos y de su régimen jurídico de organización y funcionamiento; y los servicios públicos considerados esenciales que se prestan a los ciudadanos y usuarios del Estado legitimados para ello $^{55}$. Por otra parte, en el sistema liberal-democrático el modelo descentralizador consagra diferentes formas de ejecución, entre los que destacan aquellos casos que, con diferentes variantes políticas y administrativas, se dan dentro de los Estados que pertenecen a la Unión Europea con un modelo federal o compuesto ${ }^{56}$.

Estas circunstancias se presentan de forma singular en el caso del Estado español que en la descentralización de la gestión pública incluye sus diferentes formas, como son, la desconcentración administrativa, la autonomía institucional o empresarial pública con estructuras de privatización formal o material y el reparto de competencias de soberanía con carácter político en el ámbito territorial. Todas ellas se presentan como un medio para aumentar la eficacia de la actividad administrativa, pero también como causantes de la posible pérdida de eficacia jurídica del principio de responsabilidad ${ }^{57}$. La misma heterogeneidad

${ }^{55}$ Se señala la doctrina, en un enfoque positivo del Consejo Constitucional francés, decisiones 25-26 de junio de 1986, de la distinción entre servicios públicos constitucionales y servicios públicos creados por el legislador que se relacionan en el plano objetivo con las funciones de soberanía, por definición no privatizables y los demás, donde puede concurrir en su prestación el sector público y el privado. En contrapartida la obligación de no privatización no prohíbe la relación contractual con un órgano privado para su prestación. Es en la limitación de aplicar criterios de interpretación constitucional para el primer supuesto, o en la delimitación de las modalidades o efectos contractuales en el segundo donde se permite una evolución a formas descentralizadas de gestión ya sea en primer término en los servicios constitucionales no esenciales o más adelante en el ámbito de las funciones de soberanía Vid. Muñoz Machado, Santiago. Servicio... Op. Cit. págs. 123-126.

${ }^{56}$ Para entender los matices entre ambos modelos, o dicho de otro modo, la pertenencia de ambos conceptos a un marco jurídico-político común. Vid. FERNÁNDEZ Manjón, Desiderio. La colaboración en el Estado compuesto asimétrico. El caso de España. Oñate, IVAP, 2001. pág. 61.

${ }^{57}$ Peces Morate alude a la responsabilidad como principio general del Derecho que como tal se superpone a la legislación positiva que «tiene su fuente o raíz en un principio general del derecho, cual es que cada uno debe responder de sus propios 
latente en las formas de descentralización parece ocasionar, ante la falta de unidad y desarrollo positivo de los criterios doctrinales, problemas en la aplicación de los principios de responsabilidad pública ${ }^{58}$. Así, mientras las actuaciones administrativas utilizan las técnicas de la organización en la aplicación discrecional del marco legislativo y reglamentario, las competencias de soberanía forman instituciones de organización política sobre el bloque de constitucionalidad con diferentes niveles de responsabilidad en la organización político-administrativa.

La responsabilidad pública se considera un principio jurídico axiológico causante directo, entre otros, de la especialidad de las relaciones entre la Administración y la sociedad, tanto en su expresión colectiva como individual, puesto que como tal las Administraciones públicas ejercen poderes en cada una de sus funciones cuya legitimación resulta indivisible en un régimen jurídico único. El principio de responsabilidad pública nace con la pérdida del concepto de soberanía como poder omnímodo en el Estado absolutista, que hace surgir la obligación del reparar todo daño indebidamente producido, creada ante la cesión legítima de una potestad administrativa por el titular de unos derechos ${ }^{59}$. La previa existencia de estos derechos subjetivos originan una tutela a través de los mecanismos de protección y control que dan lugar a un proceso especial y complejo del Derecho administrativo, pero sin entrar en él, y sus limitaciones o distorsiones, el bien que se protege es sustantivo de la función de los poderes públicos que actúan con inmunidad como atributo ordenador para tutelar los derechos públicos ${ }^{60}$.

En la medida que los poderes se desagregan en funciones que participan de diferentes criterios de organización política, técnicas de gestión administrativa y formas de ejecución de sus actividades, puede disminuir el control y las garantías jurídicas de la actividad pública, lo que se evita en la obligatoria titularidad orgánica bajo una misma norma de responsabilidad de los actos administrativos. Sin embargo, en la complejidad de las formas de descentralización administrativa, se acude a una aplicación sectorial del régimen jurídico administrativo en sus múltiples especialidades que dificulta la asun-

\footnotetext{
actos». (Peces Morate, J. E. «La responsabilidad administrativa. Últimas orientaciones jurisprudenciales» en Cuadernos de derecho local, n. 8, 2005. pág. 75).

${ }^{58}$ Vid. Schmidt-Assmann, Eberhard. Teoría general... Op. Cit. pág. 259.

${ }^{59} \mathrm{Vid}$. Altamira Gigena, Julio I. Responsabilidad del Estado. Buenos Aires, Astrea, 1973. págs. 44-45.

60 «[...] de las técnicas procesales depende la medida del derecho subjetivo. En este sentido el reglamentarismo excesivo a veces no da, si no que quita, y el derecho subjetivo fenece por deficiencias formales». (Dromi, José Roberto. Derecho subjetivo y responsabilidad pública. Madrid, Grou, 1986. pág. 15).
} 
ción de responsabilidad en la actuación pública de la administración infractora o causante de la lesión de los bienes y derechos ${ }^{61}$. En un marco de relación donde no existe la reciprocidad ni igualdad de las partes, impera como obligación pública el cumplimiento del Derecho y la legalidad. Así, en la controversia, a la obligación del usuario público de establecer el nexo de causalidad como prueba, a la Administración le corresponde cumplir las reglas de responsabilidad y reparación que por dicha descentralización a menudo se incumplen ${ }^{62}$.

\section{II.2.B. Las formas de descentralización política y administrativa y sus} efectos de responsabilidad

A fin de sustanciar la fijación de responsabilidades, la clasificación de las formas de descentralización de la organización pública requiere un criterio homogéneo que ordene funcional y organizativamente sus dimensiones políticas y administrativas para obtener un marco unificado que permita imputar la misma categoría jurídica de la responsabilidad a las diferentes formas de descentralización. Para ello el criterio jerárquico resulta significativo por su claridad, si bien las estructuras en las relaciones de responsabilidad se producen fácticamente en formas más complejas y difusas ${ }^{63}$. Sin embargo, en la propia relación contractual, como elemento más abierto de establecimiento orgánico, el criterio jerárquico es ineludible. En este sentido, la propia Teoría de la Agencia reconoce la existencia del principal y el agente, aceptando así un principio jerárquico que presenta dos sentidos de relación genéricamente considerados ${ }^{64}$. Por consi-

${ }^{61}$ Precisamente en la exposición de la introducción del principio Dromi propone «un proceso administrativo único que a través de una acción pluralice la tutela de diversas pretensiones». Ahora se trata de la dificultad de exigir responsabilidades por el propio entramado de la organización administrativa que se añade a sus procesos rígidos e individualistas, que aluden al principio de la legitimación imperante en ese momento. (Ibid. págs. 15-16).

${ }^{62}$ Véase la abundante jurisprudencia que sobre la doctrina del nexo causal aporta Peces Morate. Vid. Peces Morate, J. E. «La responsabilidad... Op. Cit. págs. 75-83.

${ }^{63}$ Como verdadero tratado inspirador de la doctrina posterior de la distinción entre las formas de descentralización pública y también en su perspectiva histórica resulta ineludible acudir a MARTín-Retortillo BAQUer, S. y Argullol, E. Descentralización Administrativa y organización política. 3 tomos. Madrid, Alfaguara, 1973.

${ }^{64}$ A pesar de su relativa actualidad, la doctrina francesa de principios del siglo XX ya utiliza el concepto de agente como figura de la Administración, tal y como recoge Ubierna de la interpretación de Dalloz: «Se deben entender por agentes del gobierno no solamente a los administradores propiamente dichos, sino aun los dependientes de las Administraciones financieras, tales como Registros, Contribuciones directas e indirectas, Aduanas, etc., los agentes diplomáticos, en fin los agentes destinados a los servicios tan diversos que responden a las necesidades de la sociedad» (cursiva en 
guiente, la clasificación organizativa basada en la descentralización administrativa asume ambos sentidos ${ }^{65}$ :

La descentralización descendente, que se caracteriza por la transferencia de competencias desde las entidades que tienen su título potestativo a diferentes órganos en la línea jerárquica de atribución de poderes, en la que se puede establecer la siguiente tipología:

a) Política: que consta de la transferencia de competencias soberanas bajo el principio democrático entre instituciones con órganos de representación directa y con capacidad legislativa o normativa en su ámbito. Por una parte se puede distinguir desde la atribución local a la regional ${ }^{66}$. Puede así considerarse que el criterio predominante de la descentralización política es el territorial. Bajo dicho criterio se asimilan ámbitos políticos diferenciados en los que confluyen motivaciones funcionales, como la mejor administración pública por la cercanía entre los sujetos de la gestión, que se acentúa en las administraciones locales. También pueden aparecer condiciones históricas, en el reconocimiento de aspectos culturales y políticos que subyacen a los caracteres institucionales de soberanía de los territorios, más propias de las administraciones regionales. Con el predomino de unas u otras, en el ordenamiento de la descentralización política, casi siempre confluyen características funcionales o históricas.

b) Administrativa: que aplica la desconcentración regida por el principio de jerarquía administrativa desde la titularidad competencial del órgano descentralizador, tales como: las administraciones periféricas; la descentralización regida por el principio de especialidad, generalmente sustanciada en entidades independientes, que vienen a ostentar una nueva titularidad

original). (UbIERna y Eusa, José Antonio. De la Responsabilidad de los órganos del Estado. Madrid, Mariano Núñez Samper, 1915? pág. 61).

${ }^{65}$ Respecto a la clasificación propuesta Daniel Sarmiento constata ambos conceptos, ascendente y descendente, en el aspecto de la coordinación. Cfr. SARMIENTo RAmIREZ-EscuDERo, Daniel. El soft law administrativo. Un estudio de los efectos jurídicos de las normas no vinculantes de la Administración. Cizur Menor, Thomson Civitas, 2008. págs. 50-60.

${ }^{66}$ En ambos casos se trata de una atribución de competencias constituyente, no por cesión, delegación u otro tipo de otorgamientos por otras entidades públicas, por ejemplo, los principios de autonomía local o las competencias políticas de las Comunidades Autónomas no proceden de la Administración General o el Gobierno del Estado, aunque todas ellas se encuentren sancionadas por leyes emanadas del Parlamento o las Cortes, su origen se encuentra amparado por la norma constitucional. 
ejecutiva bajo el control político del órgano administrativo cedente de competencias y funciones ${ }^{67}$; la privatizadora, que se otorga sobre regímenes jurídicos separables en los actos bajo tutela pública de cesión y ejecución de la gestión, y de titularidad privada bajo la regulación fijada en las cláusulas de la cesión de explotación de bienes y servicios; por último, y dentro de la anterior clase, las organizaciones privadas de interés público, bien desde la tutela de un régimen jurídico administrativo específico para el ejercicio de competencias subsidiarias de la Administración (administraciones independientes como los Colegios y asociaciones profesionales,...), o en organizaciones de actividad social sin interés mercantil, también bajo tutela especial por el régimen jurídico administrativo (Organizaciones no gubernamentales, Fundaciones, ...).

El segundo sentido de relación establece una descentralización ascendente que consiste en la cesión de competencias desde los órganos potestativos a entidades de distinta titularidad y rango jurídico político. A diferencia de la anterior, la descentralización ascendente origina típicamente nuevos órganos e instituciones que concentran competencias descentralizadas de los Estados cedentes y centralizadas para los cedidos. Análogamente a la descentralización descendente, dichas competencias diferencian cualitativamente los siguientes tipos de relación:

a) Políticos. Tratados internacionales y acuerdos constitucionales, cuando los órganos de soberanía cedentes son Estados que acuerdan formar nuevas instituciones donde se depositan las competencias cedidas, tales como las instituciones supraestatales cuyo ejemplo más preclaro es la Unión Europea, pero propio también de los sistemas confederales en la creación de instancias estatales ${ }^{68}$. En ambos casos se da lugar a nuevas ins-

${ }^{67}$ Una formulación de éxito apoyada en la teoría de la eficacia de la descentralización en la que confluyen tanto los conceptos político territoriales como administrativos, aunque con aplicaciones posteriores muy selectivas, la encontramos en Rodríguez Arana, que desarrolla las tesis propuestas por Fraga Iribarne. Vid. Fraga IrIBARne, Manuel. Administración única. Una propuesta desde Galicia. Barcelona, Planeta, 1993. Vid. Rodríguez-Arana MuÑoz, Jaime. "Administración Única: descentralización y eficacia» en El futuro del Estado Autonómico (ed. J. Rodríguez-Arana Muñoz, y A. Díaz Otero). Santiago, Fundación Caixa-Galicia, 1996.

${ }^{68} \mathrm{El}$ modelo confederal resulta prácticamente inexistente en la práctica, aunque el sintagma hace referencia a un concepto asimilable a determinadas situaciones concretas dentro del sistema federal. También respecto a los usos del concepto de federalismo Vid. Fernández MAnjón, Desiderio. La colaboración... Op. Cit. págs. 49-56. Para una buena caracterización con un buen ejemplo comparado 
tituciones de Derecho público. La preexistencia de sistemas jurídicos e institucionales propios entre los Estados participantes puede dar lugar a organizaciones que establecen relaciones heterogéneas, tanto en los órganos jurisdiccionales, administrativos o en los políticos de gobierno ${ }^{69}$.

b) Administrativos. Acuerdos de cooperación entre administraciones de gobiernos estatales, regionales y entidades locales o repartos competenciales por reserva de ley ${ }^{70}$. Estos dos últimos casos pueden a su vez ser internos, cuando dichas instituciones pertenecen al mismo Estado, como las mancomunidades o entidades supralocales (Diputaciones, comarcas, cabildos y consejos insulares,...), e interregionales, por convenios entre regiones o comunidades autónomas; o externos, cuando los sujetos participantes se encuentran en Estados diferentes, como las instituciones transfronterizas o interregionales (eurorregiones, ciudades transfronterizas,.... $)^{71}$.

Como elemento común, en todos los casos se transfieren poderes y competencias, en definitiva, funciones de la organización administrativa de los Estados y de sus entidades territoriales, pero también dentro de éstos, constituidos como administraciones de rango constitucional, entre sus órganos e instituciones políticas. De algún modo esta doble vinculación político-administrativa, siendo de fundamentación jurídica ampliamente diversificada, establece una nueva conexión entre el ordenamiento constitucional y administrativo en la organización pública. Tanto la descentralización de afectación funcional y política, en el caso de la distribución competencial territorial

de las instituciones supranacionales poniendo énfasis en el carácter federal de la UE. Vid. CHITI, Edoardo. «Organización Europea y Organización global: elementos de una comparación» en Derecho administrativo global. Organización, procedimiento, control judicial (Ed. Ponce SolÉ, Juli). Madrid, INAP-Marcial Pons, 2010. págs. 33-78.

${ }^{69}$ Este tipo de heterogeneidad se pone de manifiesto en las declaraciones anejas y protocolos particularizados a los Estados en los Tratados de la UE, como los que se producen en el Acta Final de la Conferencia intergubernamental que adoptó el Tratado de Lisboa.

${ }^{70}$ Forman parte de estas últimas las leyes de Régimen Local a nivel estatal y autonómico que ejecutan las previsiones constitucionales de los principios de autonomía local establecidos en el artículo 140 y en el Título VIII, Capítulo II, CE y sus desarrollos en los respectivos Estatutos de Autonomía.

${ }^{71}$ En la obra de Fernández Manjón se puede encontrar este modelo de organización territorial, donde conviven los aspectos jurídicos y políticos, internos y externos de la descentralización administrativa, tomando diferentes casos empíricos de la realidad europea y particularmente en España en el campo de las instituciones transfronterizas. Vid. FERNÁNDEZ MANJÓN, Desiderio. Proyección internacional de la diversidad territorial. Oñati, IVAP, 2003. págs. 207-268. 
basada en principios de autonomía local o federales, como la desconcentración de competencias y funciones de órganos de gobierno a entidades administrativas y empresariales públicas, pertenecen a una misma sustancia descentralizadora. Con la modernización administrativa, particularmente en el caso de España precedida de un nuevo ordenamiento constitucional, se puede ver cómo el fenómeno descentralizador, ampliamente considerado, presenta una finalidad de mejora de la eficacia en el servicio del Estado a los ciudadanos bajo las cláusulas social, democrática y de cumplimiento de la legalidad enunciadas en dicho ordenamiento.

\section{II.2.C. Descentralización y control de la responsabilidad pública}

Considerada en esa finalidad de fundamentación constitucional, la descentralización de la organización administrativa comparte un principio común de responsabilidad pública reconocido en la responsabilidad política del gobierno, la responsabilidad administrativa sustanciada en el régimen jurídico-administrativo general y de forma específica en la responsabilidad patrimonial, que constituye una de los contenidos típicos de la actividad de las Administraciones Públicas. Por consiguiente, el bloque de responsabilidad pública instruye procedimientos generales y procedimientos especiales de responsabilidad administrativa, todos ellos concernidos por la actuación formal y material fundada en la teoría de los actos, que sólo contempla aquellos jurídicamente garantizados. Sin embargo, aun considerando este aspecto como una limitación, conlleva tanto en su formulación doctrinal como en su desarrollo positivo, un conjunto común de principios ${ }^{72}$.

La correlación entre las técnicas de descentralización, que reciben un fuerte impulso afín a toda la estructura de la Administración en los procesos de modernización administrativa, y la responsabilidad pública como principio propio que afecta a las dimensiones política, jurídico-administrativa y económica del Estado, es en sí misma contradictoria. Si dentro del Estado del Bienestar se produce un modelo burocrático y una quiebra de la responsabilidad patrimonial en la crisis del déficit público, posteriormente, la introducción de la nueva gestión pública y su modelo privatiza-

72 «La existencia de una variedad de procedimientos y normas sectoriales no significa que carezcan de unas características comunes [...] En este sentido, los procedimientos especiales de responsabilidad suponen adaptaciones o complementos de la regulación general del instituto de la responsabilidad a casos o sectores concretos». (Colom Piazuelo, Eloy. Los Procedimientos Especiales de Responsabilidad Administrativa. Cizur Menor, Thompson Aranzadi, 2007. pág. 25). 
dor provoca un alejamiento de la responsabilidad política y administrativa del Gobierno y la Administración en las obligaciones de control e intervención sobre los sectores privados afectados por el interés público. En este sentido tal vez puede considerarse que en cualquiera de estas fases de desarrollo del Estado liberal democrático, el régimen jurídico administrativo puede, al quebrar su función sistematizadora, sufrir la pérdida de capacidad de dirección de la organización pública.

Por otra parte, la relación entre la responsabilidad y la inseguridad jurídica en los procesos de descentralización no tiene los mismos efectos para los servicios públicos directos, identificados anteriormente en sentido estricto por el carácter divisible de las actividades prestacionales, que en los servicios administrativos y funciones de autoridad, cuya disposición atañe frecuentemente a resoluciones normativas de aplicación general con resultados inmateriales. Mientras que la actividad prestacional puede beneficiarse en su ejecución por la cercanía de las administraciones a los interesados y la mayor eficacia alcanzada en la gestión por la participación e interactuación con los usuarios de los servicios públicos, la actividad administrativa basada en actos jurídicos fundados en el ejercicio de potestades, que afectan al reconocimiento de derechos, se ven más alteradas en la consecución de sus fines por el posible detrimento de la responsabilidad pública en las disposiciones descentralizadas. En cualquiera de los casos los problemas de coordinación, o la pérdida de una responsabilidad única e identificable que haga efectiva la ejecución de las obligaciones de la Administración puede desembocar en una menor eficacia jurídica del principio de igualdad.

Ante la fijación de la responsabilidad en todas las formas de descentralización política y administrativa que incluyan las técnicas privatizadoras introducidas en la nueva gestión pública, se promueve la hipótesis de una tendencia a la disolución de la responsabilidad pública. En primer lugar como consecuencia de la pérdida de la institución de la responsabilidad asentada en los procedimientos especiales aplicados a la actividad administrativa. Colom Piazuelo identifica para esta institución la figura central de la responsabilidad de los daños y perjuicios por la actuación legal de la Administración o ilegal de sus funcionarios que desemboca en la obligación indemnizatoria. Junto a ella también aparece la figura de la compensación por los actos no imputables directamente a la Administración, pero que se justifican ante razones de equidad o solidaridad social, como los daños de guerra, ya reconocidos en el siglo XIX, o recientemente por actos terroristas. Desde su origen la Administración fue reconocien- 
do la responsabilidad por sus actos a la vez que limitando ésta responsabilidad a la directa ejecución de sus servicios ${ }^{73}$. A esta limitación concurren los procedimientos especiales de responsabilidad regulados en normas sectoriales como la expropiación o la contratación, que da lugar a la determinación indirecta del sujeto responsable del daño a través de la solicitud a la Administración de su determinación ${ }^{74}$. También existen otros procedimientos como el recurso de anulación del acto que permite solicitar la indemnización como pretensión accesoria o sencillamente evitar la limitación de derechos. Finalmente la tendencia a regular supuestos específicos a través de procedimientos especiales de la responsabilidad adaptados a diversos sectores de actividad, sin abandonar el carácter supletorio del procedimiento general de la Ley 30/1992, de 26 de noviembre, de Régimen Jurídico de las Administraciones Públicas y del Procedimiento Administrativo Común ${ }^{75}$.

En el fenómeno privatizador la institución de la responsabilidad no ha podido, en su efecto indemnizatorio, aplicarse en situaciones limitativas a menudo expresamente enunciadas por normas especiales. Así, en las normas que amparan la privatización interna de los servicios públicos, como la Ley de Contratos de las Administraciones Públicas aprobada en el Real Decreto Legislativo 2/2000, de 16 de junio, por el que se aprueba el texto refundido, se comienza a limitar la responsabilidad administrativa al admitirse sin protección pública algunas cláusulas de responsabilidad indirecta de los sujetos que intervienen en el daño causado por la ejecución del contratista (artículo 219 RDL $2 / 2010)^{76}$. Se manifiesta así la tendencia del marco jurídico a limitar la responsabilidad administrativa a partir de los procesos de descentralización, que habilitan diferentes regímenes o condiciones particulares de entidades y personificaciones para el ejercicio de posibles descargas de responsabilidad.

${ }^{73}$ Vid. Colom Piazuelo, Eloy. Los Procedimientos Especiales...Op. Cit. pág. 55.

${ }^{74}$ Este ligamen debe verse con todas las cautelas, como muestra la diferenciación de la institución expropiatoria y de responsabilidad patrimonial en la STS 6268/2013.

${ }^{75}$ Vid. Ibid. pág. 57.

${ }^{76}$ Estas limitaciones tienen antecedentes en los casos iniciados a favor de la reclamación civil al ejecutor predominante en la obra pública o el régimen concesional en el siglo XIX. Véase el Real Decreto de 18 de diciembre de 1890, que regula la indemnización causada por la industria minera a la agricultura. Actualmente, en la misma materia del sector minero la STS 6023/2013, unida la causa en la jurisdicción contenciosa, se falla una responsabilidad solidaria entre el privado autorizado y la Administración. 


\section{DINÁMICA JURÍDICA DEL DERECHO ADMINISTRATIVO EN LA IMPLANTACIÓN DE LAS TÉCNICAS DE GESTIÓN PÚBLICA}

A lo largo del proceso de modernización y transformación de la gestión pública el Derecho administrativo se ve sometido a una dinámica de adaptación y sustitución de sus instrumentos jurídicos por técnicas que acompañan los principales ámbitos de actuación administrativa. Dicha sustitución pretendida no alcanza a cumplir determinadas funciones reguladoras que sirven como mecanismos de seguridad, garantía de los sujetos que conforman el sistema y guía de la actividad administrativa que, sin embargo, se alcanzan bajo el principio de la eficacia jurídica. Por otra parte, el despliegue del Derecho en los nuevos ámbitos, de acuerdo con el cumplimiento de sus funciones, no sólo depende de la mera asimilación, ni tampoco, abstención en la dedicación a ellos. Todo indica que los fenómenos de la gestión pública, entre los que se incluyen las técnicas incorporadas, se establecen, como toda realidad efectiva constituida en objeto de estudio, en fuente del propio marco jurídico público, que al tiempo que los incorpora a su acerbo ve transformadas sus características sin alterar por ello la finalidad de la disciplina que aborda.

Es bajo esta perspectiva como se plantean los epígrafes finales. Se trata de considerar determinados casos destacados en los que la gestión pública plantea problemas que más allá de sus cuestiones prácticas invitan a, cuando menos, analizar los nuevos planteamientos heurísticos sin descartar incursiones epistemológicas en la disciplina del Derecho administrativo. Entre ellos encontramos nuevos conceptos, tales como los instrumentos del Derecho indicativo o soft-law y la afluencia de lo que se van a denominar normas técnicas que sustituyen en las relaciones administrativas a los principios rectores del marco jurídico. Todo ello con el horizonte puesto en una visión integral de la Administración Pública en la búsqueda del esclarecimiento y la formulación de respuestas rigurosas y científicas a los interrogantes que suscita la misión gestora de las relaciones entre el ámbito público y privado en el sistema político liberal-democrático.

\section{III.1. Los nuevos desarrollos normativos}

Es posible apreciar la ineficacia de los objetivos desreguladores en las funciones nuevas y tradicionales del Estado liberal, a causa, entre 
otros factores, de la aparición de nuevos tipos dispositivos aplicados a las actuaciones de naturaleza jurídica ${ }^{77}$. De hecho se detectan efectos similares en ambos sustratos de la actividad administrativa, tales como, entre otros: el predominio de estructuras burocráticas; la división competencial y especialización funcional en el establecimiento de servicios públicos y de responsabilidades en el cumplimiento de los objetivos; la titularidad de la Administración en la prestación de los servicios públicos, sea de forma directa o indirecta por cesión contractual; la vinculación de los servicios públicos a directrices jerárquicas formales de desconcentración y descentralización ante la ausencia de otras formas de coordinación eficaces, excepto, claro está, en los casos de privatización material de aquellos.

En el aspecto externo, la gestión pública recurre a arquetipos económicos para los que las regulaciones inapropiadas revierten en costos y precios más elevados, en suma, en una deficiente asignación de recursos para el conjunto de la economía. Esto justifica la reforma con criterios técnicos aplicados a contenidos de regulación, poderes de supervisión a la autoridad administrativa delegada, grado de discrecionalidad e independencia de ésta, forma de nombramiento de sus dirigentes, régimen de personal, procedimientos, derecho de participación por sectores interesados, grado de revisión judicial y supervisión legislativa ${ }^{78}$. Se argumenta para ello el coste de las regulaciones en términos de cumplimiento agregado por ciudadanos o sectores implicados y su repercusión en el PIB, si bien, se abstraen los riesgos de la desregulación, que sólo pueden medirse hipotéticamente o a posteriori, pero que indudablemente existen ${ }^{79}$.

${ }^{77}$ Se introduce en este sentido la categoría definida por Daniel Sarmiento de softlaw que por su carácter formal condiciona la elaboración reglamentaria de las disposiciones generales, si en éstas se hace referencia a la cualidad jurídica del acto administrativo de carácter singular, aquel tiene un efecto plural, con su correspondiente indeterminación jurídica en la que se ahondará más adelante. Vid. SARMIENTO, Daniel. El soft law administrativo... Op. Cit. págs. 93-94.

${ }_{78}$ "La cuestión real es qué clase de regulaciones (incluyendo las que hace posibles los mercados) promueven el bienestar humano en diferentes contextos y como conquistar la capacidad para producir y administrar eficazmente tales regulaciones» (Prats Catalá, Joan. «Las transformaciones... » Op. Cit. pág. 72). Entre los citados por Prats. Vid. SunsteIn, C. R. Free markets and Social Justice. New York. Oxford University Press. 1997. Vid. HorN, M. J. The political economy in Public Administration. International choice in the Public Sector. Mass, Cambridge U. P., 1995. Sobre la reforma regulatoria cabe destacar el informe de la OCDE y sus recomendaciones acerca de la reforma de las regulaciones en España, al respecto, tal y como se destaca en el texto de Joan Prats. Vid. OECD reviews of regulatory reform, Regulatory Reform in Spain, París: Governance, OECD, 2000.

${ }^{79}$ Vid. Prats Catalá, Joan. Las transformaciones...» Op. Cit. pág.76. Serviría de ejemplo de medición a posteriori confrontar los beneficios acumulados por la desre- 
En el aspecto interno, se considera que las políticas de gestión pública forman parte de los requisitos de las políticas públicas. En ellas, las técnicas de organización y gestión concurren con los medios de regulación y garantía que pertenecen a la esfera jurídica. La concurrencia entre la indeterminación de las técnicas de gestión y organización en las políticas públicas y las normas de naturaleza jurídica se establece en el marco de la regulación ${ }^{80}$. Así, si la regulación es estrictamente jurídica producirá una determinación clara de reglas binarias susceptibles de resolverse en el terreno jurisdiccional, o por el contrario, si es fundamentalmente técnica desarrollará una vinculación a su cumplimiento con mecanismos de control leves.

El ámbito jurídico de esta regulación técnica se cubrirá utilizando la técnica jurídica del soft-law, entendida como conjunto de normas indicativas de finalidad genérica y cumplimiento no vinculante que tratan de influir en los actos ejecutivos y normas vinculantes. Encontramos una definición del término en Ton Duijkeersloot dentro de su análisis de las políticas de regulación de los mercados financieros ${ }^{81}$. El origen de estos instrumentos se sitúa en los acuerdos internacionales no vinculantes que se oponen a la esencia de los Tratados con reglas quasi legales que, por otra parte, pueden afectar a la conducta del Estado ${ }^{82}$ :

soft law is a phenomenon that is, especially common in international law. It is undisputed thar historically, there are two main sources of international law: treaties and customary law. Soft law is a third source of international law that is developed rapidly in recent decades, especially to deal with sensitive matters such as human rights, the protection of the environment, bioetical issues and alco financial market regulations. The category of softlaw includes a great variety of instruments: declarations, recommendations, charters, resolutions, et al.

gulación de los mercados financieros con los costes de la crisis iniciada en el año 2007 en este sector

${ }^{80}$ El loable intento de determinar estos objetivos a través de indicadores cuantitativos no colma las aspiraciones de su cumplimiento, como muestra el peso de los estándares de percepción y cualitativos en la medición, por ejemplo, de las cartas de servicio. Vid. Raposo Villamor, José Manuel y TorRado SANCHO, Julián. "Compromisos con los ciudadanos de Murcia» en UNE. La Revista de AENOR, n. 237, Abril 2009.

${ }^{81}$ Vid. DuiJKersLoot, Ton. «The Principle of Legality and the 'Soft Law' Regulation and Supervision of Financial Markets « en The Eclipse of the Legality Principle in the European Union. (ed. Besselink, Leonard, Pennings, Frank y Prechal, Sacha). AH Alphen aan den Rijn, Kluwer Law International, 2011. págs. 169-186.

${ }^{82} \mathrm{Ibid}$. pág. 173. Para una exposición sistemática del concepto de soft-law vinculado al Derecho Internacional y particularmente al ejercicio de las funciones de la UE, dentro de un estudio de la legislación tributaria comunitaria. Vid. SARMIENTo RAMIREZ-EscudERo, Daniel. «The Function of EU Soft Law» en Traditional and Alternative Routes to European Tax Integration, (ed. Dennis Weber). Amsterdam, IBFD, 2010. págs. 53-66. 
Bajo este soporte conceptual aparece una doctrina que se pronuncia por la calidad regulatoria, es decir, la definición de reglas para establecer las políticas públicas que, en gran medida, se ejecutan de forma desregulada a causa de los problemas para abarcar legislativamente la dinámica operativa de la actividad privada.

Estas normas dan cabida a todos los fenómenos, pero al mismo tiempo son inútiles a la hora de dar una respuesta a un caso. El legislador ve en ellas una solución a sus limitaciones que incluso pueden llegar a tomar otro cariz: ante su incapacidad para alcanzar a los operadores regulados, deja en sus manos la concreción de esas normas abiertas. Surge así una suerte de delegación normativa con intencionalidad politica (que sean otros quienes tomen la decisión), cuya naturaleza normativa y efectos nadie conoce con seguridad, pero que da al legislador la confianza de que, esta vez sí, su voluntad se adaptará a la necesidad de los tiempos. Una forma de legislación que ha sido bautizada como legislación simbólica, y que entronca directamente con el auge contemporáneo del soft law la $^{83}$.

La caracterización y definición de este fenómeno se va perfilando por varios autores. Para Linda Senden existen tres elementos clave de la soft law: uno, está afectado por un conjunto de reglas y compromisos; dos, existe un acuerdo cuyas reglas y compromisos no tienen un efecto legal; tres, su ánimo pretende encontrar efectos prácticos o impacto en la conducta: "Rules of conduct that are laid down in instruments which have not been attributed legally binding force as such, but nevertheless may have certain -indirect-legal effects, and that are aimed at and produce practical effects» ${ }^{84}$. Para Daniel Sarmiento el concepto queda delimitado por un conjunto de características aportadas: uno, segmento del ordenamiento creador de normas de cumplimiento en grado, cuyo incumplimiento no entraña una respuesta jurídica concreta; dos, impulsor de los poderes públicos a espacios competenciales jurídicamente impropios; tres, sujeto a procedimientos que para desplegar efectos ad extra no requieren su aprobación pero sí su publicación; y cuatro, manifestación de sus efectos en las reglas antes que en los principios ${ }^{85}$.

${ }^{83}$ Vid. SARMIEnTo, Daniel. El soft law administrativo...Op. Cit. pág. 38. Respecto al concepto de legislación simbólica expresado como una especie de deliberada falta de eficacia jurídica que se conecta con la falta de seguridad jurídica, véase MARCILLA CóRDOBA, Gema. Racionalidad legislativa: crisis de la Ley y la nueva ciencia de la legislación. Madrid. Centro de Estudios Políticos y Constitucionales, 2005. pág. 88.

${ }^{84}$ SENDEN, Linda. "Soft Law, Self-regulation, and Co-regulation in European Law: Where do they meet» en Electronic Journal of Comparative Law, v.9, n. 1, 2005. pág. 22.

${ }^{85}$ Vid. Sarmiento, Daniel. El soft law administrativo...Op. Cit. págs. 105-106. Se encuentra su antecedente en SARMIENTo RAmirez-Escudero, Daniel.» La autoridad del Derecho y la naturaleza del soft law» en Cuadernos de Derecho Público, n. 28, mayoagosto, 2006. págs. 221-266. También, como trabajo iniciador de este concepto Vid.

() UNED. Revista de Derecho UNED, núm. 14, 2014 
Finalmente es posible establecer que este concepto de soft law, acuñado como Derecho Indicativo, viene determinado por el dominio político del poder ejecutivo y legislativo que trata de desprenderse del poder judicial dictando normas que sólo vinculan a la propia Administración con reglas que actúan como parámetro de conducta y se dotan de un valor normativo concreto que goza de «inmunidad ante la actuación jurisdiccional ${ }^{86}$. En definitiva, para Daniel Sarmiento el escenario de la soft law es consecuencia de la emergencia del poder ejecutivo sobre el legislativo y judicial con el control de ambos por el poder político instrumentado en los partidos, verdaderos detentadores, una vez acceden electoralmente al gobierno, de las políticas públicas.

A este marco se circunscriben también la proliferación de otros instrumentos legislativos y reglamentarios otorgados al gobierno tales como el Decreto-Ley, que se ampara en la laxa doctrina del Tribunal Constitucional de la "extraordinaria y urgente necesidad ${ }^{87}$. Por último, como constata el propio Sarmiento, se constata que el propio Gobierno comienza a depositar las potestades de regulación y gestión en los actores privados por razones técnicas de eficacia enmarcadas en los procesos de reforma asociados a la gobernanza, doctrina política que, entre otras motivaciones fácticas, fomenta en el ámbito continental la participación público-privada y las medidas de desregulación:

La búsqueda de nuevas técnicas de legitimación, la globalización económica, la realidad multicultural de las sociedades occidentales y otros fenómenos que ponen en jaque las técnicas tradicionales de gestión administrativa, han provocado un debate sobre la necesidad de buscar nuevas perspectivas para la intervención de los ejecutivos, donde destaca con luz propia el empleo del soft-law ${ }^{88}$.

Alonso García, Ricardo. «El Soft Law comunitario» en Revista de Administración Pública, n. 154, 2001. págs. 63-94.

${ }^{86}$ Ibid. pág. 42.

${ }^{87}$ Vid. SALOM Guerrero, Enrique. Crisis y cambios en las relaciones ParlamentoGobierno 1993-1996. Madrid, Tecnos, 2000. págs. 48-49. Sobre la continuidad de la pérdida de poderes parlamentarios, del mismo autor. Vid. SALOM GUERRERo, Enrique. «El parlamento español en la VII legislatura: una deriva negativa» en Circunstancia, Fundación Ortega-Marañón, Año II, n. 4, Mayo 2004. <http://www.ortegaygasset.edu/ fog/ver/372/circunstancia/ano-ii---numero-4---mayo-2004/ensayos/el-parlamento-espanol-en-la-vii-legislatura--una-deriva-negativa\#52> (consultado el 24 de marzo de 2012). Sólo la II, III y VII legislatura han sido de mayoría absoluta por un partido, a la que ahora se incorpora la X, cuyo análisis aún necesita perspectiva, por consiguiente esta legislatura VII ilustra bien la consolidación de los efectos prácticos del declive parlamentario y las consecuencias del ejercicio de los amplios poderes ejecutivos del gobierno y los partidos que los amparan consagrados en el sistema constitucional.

${ }^{88}$ Vid. Sarmiento, Daniel. El soft law administrativo... Op. Cit. pág. 49. 
Amparados en este concepto llevado a la práctica debe observarse que la relación entre el Derecho Indicativo, de carácter admonitorio, y la normativa vinculante, que otorga garantías y eficacia jurídica a la ejecutoriedad administrativa o las resoluciones cuasi-jurisdiccionales, permite explorar vías para el desarrollo del Derecho Administrativo, tales como: la sistematización del conocimiento adquirido en ámbitos autorizados de decisión legitimados y especializados; la ampliación del margen de actuación de los operadores jurídicos al expandir su espectro de decisión y negociación; el perfeccionamiento de las decisiones jurídicas en el ejercicio de potestades discrecionales ante la prescripción de criterios y pautas de decisión circunscritos a la resolución específica de cada acto administrativo; y finalmente, la asunción de conocimiento técnico que subsana las carencias de los órganos del poder público en cada caso concreto ${ }^{89}$.

Esta conexión parece que sitúa los límites del sistema jurídico con el desarrollo de la actividad administrativa dentro de cauces normativos atípicos y muchas veces impugnables desde aquel. Por otra parte, obliga a crear mecanismos de eficacia jurídica, es decir, en el marco del Estado de Derecho, transponiendo los instrumentos indicativos a normas más deterministas que utilicen su valor heurístico y permitan la adaptación de las fuentes jurídicas al conocimiento cambiante de la realidad. Presta así un material a las normas jurídicas allí donde la eficacia meramente formal tal vez tolera una discrecionalidad que, completamente fuera del marco jurídico, puede provocar el comportamiento arbitrario de la Administración.

Resulta por consiguiente imperativo abordar la relación que deben guardar los instrumentos del soft law con el principio de legalidad. Desde este punto de vista no se advierten inicialmente importantes problemas en el contexto de la UE, al aparecer el soft law como no vinculante no entorpece el ejercicio de la autoridad pública basado en la hard law de las directivas europeas y la legislación nacional. Sin embargo, aparecen riesgos por las posibles discrepancias entre dicha legalidad y el uso de los múltiples instrumentos de soft law debido a que se fijan compromisos que requieren elementos esenciales del principio de legalidad, cuya formulación se exige en el marco político por el legislador legitimado democráticamente para ello, que puede quedar al margen o al menos incoado a adquirir esos compromisos. Inicialmente, la mitigación de este riesgo presenta los mecanismos de control judicial y democrático ex-post, que deben jugar el papel de cubrir el vacío al respecto ${ }^{90}$.

${ }^{89} \mathrm{Vid}$. Ibid. págs. 67-68.

${ }^{90}$ El análisis se realiza dentro del examen del uso de los instrumentos de soft law en el trascendental campo de la regulación de los mercados financieros. Vid. DuI- 


\section{III.2. Las normas técnicas en el marco jurídico público}

En los procesos de modernización y reforma de la gestión pública, la trasposición de métodos y técnicas de la gestión privada al ámbito de la Administración encuentra en la proliferación de normas técnicas uno de sus rasgos, que además de penetrar en la regulación de la prestación de servicios públicos y la actividad de fomento económico y social, se incorporan a la gestión de los servicios de ejercicio de autoridad y limitación de derechos ${ }^{91}$.

En los dos últimos se encuentran las funciones más vinculadas a los contenidos típicos clásicos, o servicios esenciales, aquellos que se encuentran entre las competencias indelegables reservadas al ejercicio de la soberanía que garantizan la existencia del Estado. Los servicios públicos no esenciales son plenamente delegables al sector privado, siempre que en aquellos así previstos constitucionalmente se garantice el acceso a su prestación universal ${ }^{92}$. El carácter indelegable de los servicios afecta a la titularidad, control político y administrativo por el Estado, que debe garantizar su prestación eficaz, pero no en cuanto a la ejecución, que puede ejercerse de forma indirecta.

Como premisa de la conjugación de las normas técnicas en el marco jurídico público conviene realizar un acercamiento a los caracteres definitorios de la norma jurídica pública. En primer término figura su carácter obligatorio, rasgo compartido con la doctrina iusprivatista de la autonomía de la voluntad y la teoría normativa del negocio jurídico en su dimensión potestativa, al situar al Estado, que confiere poder a los individuos, como fuente de cualquier derecho y efecto jurídico subjetivo ${ }^{93}$.

JKersloot, Ton. «The Principle...»Op. Cit. pág. 186.

${ }^{91}$ Podemos remitirnos al debate doctrinal sobre la clasificación de las actividades administrativas, iniciado en España por Jordana de Pozas y seguido por Villa Palasí y Garrido Falla. Vid. Jordana De Pozas, Luis. «Ensayo de una teoría del fomento en el Derecho administrativo». Revista de Estudios Políticos, n. 48, 1949. págs. 41-54. Vid. Villar Palasí, José Luis. «La actividad industrial del Estado en el Derecho Administrativo» en Revista de Administración Pública, n. 3, 1950. págs. 53-129. Vid. GARRIDO FAlla, Fernando. «Sobre el Derecho administrativo y sus ideas cardinales» en Revista de Administración Pública, 7, 1952. págs. 30-31.

${ }^{92}$ En su clasificación fundacional de la doctrina administrativa en España, Jordana ya menciona la distinción de ambos tipos de actividad pública por su relación con las privadas: «Dejando aparte casos muy singulares, ni la policía ni la justicia pueden constituir actividades privadas, mientras que todas las necesidades a que atienden los servicios públicos propiamente dichos han sido históricamente satisfechas por procedimientos de derecho privado y pueden volver a serlo si cambian las circunstancias». Vid. Jordana De Pozas, Luis.»Ensayo...» Op. Cit. pág. 46.

${ }^{93}$ Manuel de la Puente, autor principal del Código Civil y figura jurídica monumental en Perú, afirma que «Según esta teoría [normativista], los particulares al ce- 
En sus diferencias, las normas públicas y privadas presentan entre otros principios ordenadores, la garantía de los intereses públicos para las primeras y la protección de la igualdad jurídica en la concurrencia de los intereses particulares en las segundas. Así, la obligación reguladora del Estado es mayor en el Derecho administrativo que en las relaciones jurídicas establecidas entre particulares, a los que se delega la potestad condicionada por la regulación pública en los casos de posible desigualdad material entre las partes por diferencia patrimonial, situación de monopolio o concurrencia con otros derechos individuales o públicos protegidos. Es decir, en general, mientras que la regulación Administrativa es unilateral y regida por el principio de tutela de los intereses generales, en las relaciones jurídicas privadas la tutela se confía a la autorregulación de las partes afectadas ${ }^{94}$. No obstante, en ambos casos, como se ha mencionado al principio, la norma jurídica presenta el carácter obligatorio del deber de su cumplimiento y punitivo por la acción coercitiva a que se somete el sujeto infractor ante su vulneración, ejecutada por los procedimientos encuadrados en la forma jurídica jurisdiccional, garantizadora por ello de los principios del Derecho.

En su unidad, a las normas jurídicas se oponen las normas técnicas no asimiladas a la juridicidad. Para la norma técnica el incumplimiento tiene consecuencias delimitadas por los riesgos inherentes a su publicidad o, en su caso, a la eficacia del ámbito privado en que se reglamente, siempre conforme con el ordenamiento jurídico general, en el que no es exigible la ejecución con carácter punitivo, cuya exclusividad corresponde al Estado, a menos que exista el encuadramiento de la norma técnica en otra norma jurídica que sea invocada para ello. Ampliando la noción, el cumplimiento de las normas técnicas no subsumidas por el Derecho, encuentra como elemento garantizador al interés privado, que para evitar la regulación pública, legitima en doctrinas políticas y económicas el encuentro de un interés general por la racionalidad espontanea de la acción de ese interés privado, razonamiento que merece el título de hipotético ${ }^{95}$.

lebrar un contrato no constituyen un ordenamiento autónomo [...]. En otras palabras, la obligación que nace del contrato adquiere naturaleza de vínculo jurídico sólo si se inserta en el ordenamiento jurídico del Estado. Norma pública y norma privada forman, por tanto, un ordenamiento único». (DE La Puente y LaValle, Manuel. "¿Por qué se contrata?» en Fernández Cruz, Gastón y Bullard, Alfredo (ed.). Derecho Civil Patrimonial. Lima, PUCP, 1997. p. 104).

${ }^{94} \mathrm{Vid}$. Ibid. pág. 106.

${ }_{95}^{5}$ El pensamiento de la formación espontánea de reglas en los conflictos de interés, que no pretenden el orden social pero que producen beneficios para la sociedad tal vez fue iniciada por Hume. Vid. Hume, DaVid. A Treatise on Human Nature. Oxford, Norton \& Norton, 2000. 3.2.2, págs. 311-322. El concepto, ya desprovisto de 
En consecuencia a su origen en un procedimiento privado las normas técnicas no publificadas poseen carácter voluntario y negociado. En este contexto se produce la hipótesis de que la profusión de corrientes normativas técnicas para regular las actuaciones de la Administración no originadas en el Estado puede poner en entredicho la utilidad del marco jurídico-administrativo, al tiempo que el sistema de garantías resultante se supedita a las condiciones particulares de los acuerdos, que tienen como fin su cumplimiento en el seno de la actividad pública $^{96}$. Sin embargo, la actividad de la Administración ha subsumido desde sus orígenes normas técnicas en áreas esenciales que se invisten de autoridad, tal puede considerarse, entre otros, el caso del urbanismo, el medio ambiente, el control de las actividades económicas o la creación y mantenimiento de bienes públicos de interés general ${ }^{97}$. Para ello la norma jurídica viene invistiendo de autoridad a figuras técnicas y regulando entidades privadas que actúan en un marco científico-técnico delimitado y tolerado, donde el engranaje jurídico debe conformar la actuación administrativa para garantizar un bien público ${ }^{98}$.

los presupuestos éticos de Hume, quedó dibujado en la teoría clásica económica por Adam Smith, y fue ampliamente desarrollado por Hayek. Vid. HAYEK, Friedrich. The Fatal Conceit. London, Routledge, 1988. pág. 21.

${ }^{96}$ Sobre la pérdida de legitimidad del Derecho estatal viene cuestionada por diferentes corrientes entre las que Darnaculleta destaca: la teoría de sistemas que confiere al susbsistema jurídico comportamientos de aislamiento y autorreferencia respecto a otros, donde la producción de normas es un atributo de cada uno para su subsistencia (autopoiesis); el institucionalimo que fomenta la autonomía organizativa y normativa de las instituciones; el concepto de autorregulación de Habermas que plantea la necesidad de justificación o legitimación del Derecho estatal cuando interviene en otros subsistemas autorregulados; finalmente, en la parte central de su tesis, el derecho reflexivo de Gunter Teubner, que invoca para el papel del derecho la regulación de la autorregulación y la transmisión a ésta de efectos jurídicos. Vid. DARNACUlleta I GaRdella, Mercè. Autorregulación y Derecho público: la autorregulación regulada. Madrid, Marcial Pons, 2005. págs. 305-313.

${ }^{97}$ En este sentido, las primeras normas de Derecho urbanístico surgen dentro la actividad administrativa de policía para el control sanitario de las ciudades guiada por un conjunto de normas técnicas de salubridad, diseño y construcción al que se incorpora posteriormente la forma jurídica, tal y como ejemplifica la Public Health Act británica de 1875.

${ }^{98}$ Como en el ejemplo expuesto, el bien básico de la seguridad pública. 